\title{
Recognition of Microbe- and Damage-Associated Molecular Patterns by Leucine-Rich Repeat Pattern Recognition Receptor Kinases Confers Salt Tolerance in Plants
}

\author{
Eliza P.-I. Loo, ${ }^{1}$ Yuri Tajima, ${ }^{1}$ Kohji Yamada, ${ }^{2}$ Shota Kido, ${ }^{1}$ Taishi Hirase, ${ }^{1}$ Hirotaka Ariga, ${ }^{3}$ \\ Tadashi Fujiwara, ${ }^{1}$ Keisuke Tanaka, ${ }^{4}$ Teruaki Taji ${ }^{3}$ Imre E. Somssich, ${ }^{2}$ Jane E. Parker, ${ }^{2,5}$ and \\ Yusuke Saijo ${ }^{1,2,6,+}$ \\ ${ }^{1}$ Graduate School of Biological Sciences, Nara Institute of Science and Technology, Ikoma, 630-0192 Japan \\ ${ }^{2}$ Department of Plant Microbe Interactions, Max Planck Institute for Plant Breeding Research, Cologne, 50829 Germany \\ ${ }^{3}$ Department of Bioscience, Tokyo University of Agriculture, Tokyo, 156-8502 Japan \\ ${ }^{4}$ NODAl Genome Research Center, Tokyo University of Agriculture, Tokyo, 156-8502 Japan \\ ${ }^{5}$ Cologne-Düsseldorf Cluster of Excellence on Plant Sciences (CEPLAS), 40225 Germany \\ ${ }^{6}$ JST PRESTO, Kawaguchi, 332-0012 Japan
}

Accepted 25 October 2021.

In plants, a first layer of inducible immunity is conferred by pattern recognition receptors (PRRs) that bind microbe- and damage-associated molecular patterns to activate patterntriggered immunity (PTI). PTI is strengthened or followed by another potent form of immunity when intracellular receptors recognize pathogen effectors, termed effector-triggered immunity.

${ }^{\dagger}$ Corresponding author: Y. Saijo; saijo@bs.naist.jp

E. P.-I. Loo and Y. Tajima contributed equally to this work.

Current address for E. P.-I. Loo: Institute for Molecular Physiology, Heinrich-Heine-Universität, 40225 Germany.

Current address for Y. Tajima: Faculty of Life and Environmental Sciences, University of Tsukuba, Tsukuba, Ibaraki, 305-8572 Japan.

Current address for K. Yamada: Graduate School of Technology, Industrial and Social Sciences, Tokushima University, Tokushima, 770-8501 Japan.

Current address for T. Hirase: Leaf Tobacco Research Center, JAPAN TOBACCO Inc, Oyama, 323-0808 Japan.

Current address for H. Ariga: Research Center of Genetic Resources, NARO, Ibaraki, 305-8602 Japan.

Funding: This work was supported, in part, by the grants from the Ministry of Education, Culture, Sports, Science and Technology of Japan (MEXT) (numbers 18H04783, 18H02467, and 21H02507 to Y. Saijo and $19 H 03092$ to T. Taji), Deutsche Forschungsgemeinschaft (SFB670 to Y. Saijo, I. E. Somssich, and J. E. Parker), Japan Science and Technology Agency PRESTO (Y. Saijo), the Asahi Glass Foundation (T. Taji), and the Max Planck Society (Y. Saijo, I. E. Somssich, and J. E. Parker); and Ph.D. fellowships from the Japanese Government Scholarship for International Priority Programs (E. P.-I. Loo) and the Japan Society for the Promotion of Science (T. Hirase).

*The $\boldsymbol{e}$-Xtra logo stands for "electronic extra" and indicates that supplementary figures and supplementary tables are published online.

The author(s) declare no conflict of interest.

(c) (i) $(\circledast)$ Copyright $\odot 2022$ The Author(s). This is an open access article distributed under the CC BY-NC-ND 4.0 International license.
Immunity signaling regulators have been reported to influence abiotic stress responses as well, yet the governing principles and mechanisms remain ambiguous. Here, we report that PRRs of a leucine-rich repeat ectodomain also confer salt tolerance in Arabidopsis thaliana, following recognition of cognate ligands such as bacterial flagellin (flg22 epitope) and elongation factor Tu (elf18 epitope), and the endogenous Pep peptides. Pattern-triggered salt tolerance (PTST) requires authentic PTI signaling components; namely, the PRR-associated kinases $B A K I$ and $B I K 1$ and the NADPH oxidase RBOHD. Exposure to salt stress induces the release of Pep precursors, pointing to the involvement of the endogenous immunogenic peptides in developing plant tolerance to high salinity. Transcriptome profiling reveals an inventory of PTST target genes, which increase or acquire salt responsiveness following a preexposure to immunogenic patterns. In good accordance, plants challenged with nonpathogenic bacteria also acquired salt tolerance in a manner dependent on PRRs. Our findings provide insight into signaling plasticity underlying biotic or abiotic stress cross-tolerance in plants conferred by PRRs.

Keywords: biotic-abiotic stress, defense signaling pathways, elicitors, MAMPs, PAMPs, pattern recognition receptor, plant immunity, plant-microbe-environment interactions, plant responses to pathogens, salt stress tolerance

Like animals, plants have evolved an elaborate immune system to sense and adapt to disturbance caused by biotic agents. How the immune system influences abiotic stress responses remains much less understood. Plants sense and cope with fluctuating environments, while accommodating a rich diversity of microbial communities that often aid host adaptation. Conversely, environmental abiotic factors such as light, temperature, and water availability profoundly influence the mode and outcome of plant-microbe interactions (Velásquez et al. 2018). This predicts an intimate relationship between biotic and abiotic stress sensing and signaling in plants. In line with this, it is becoming apparent that immune receptors and signaling regulators also impact abiotic stress responses, positively or negatively in a context-dependent manner (Saijo and Loo 2020). However, the 
regulatory logic or molecular basis behind intricate crossregulations between biotic and abiotic stress signaling remains poorly understood.

Plant immunity largely relies on two classes of innate immune receptors; namely, cell surface-localized pattern recognition receptors (PRRs) and intracellular nucleotide-binding domain and leucine-rich repeat (LRR)-containing receptors (NLRs) (Jones and Dangl 2006). Detection of microbe-associated molecular patterns (MAMPs) and damage-associated molecular patterns (DAMPs) by cognate PRRs leads to pattern-triggered immunity (PTI), which is vital in preventing the infection of most nonadapted microbes and in restricting growth of adapted microbes, termed basal resistance (DeFalco and Zipfel 2021; Saijo et al. 2018). In turn, plant-infecting microbes, whether pathogenic or nonpathogenic, employ an array of effectors to manipulate host immunity and other processes for infection. To counter this, plants employ a repertoire of NLRs that recognize microbial effectors to mount effector-triggered immunity (ETI) that terminates microbial growth. NLRs are classified into two major subclasses, based on their N-terminal domains: the coiled-coil (CC)-NLRs and the Toll-interleukin1-receptor (TIR)NLRs. CC-NLR and TIR-NLR functions typically require the defense regulators $N D R 1$ and $E D S 1$, respectively (Jones et al. 2016). Compared with PTI, ETI is typically greater in amplitude and robustness against microbial perturbations, and is often accompanied by localized cell death called the hypersensitive response (Cui et al. 2015). Molecular genetic studies in Arabidopsis thaliana interactions with the bacterial pathogen Pseudomonas syringae pv. tomato DC3000 indicate mutual interdependence between PTI and ETI (Ngou et al. 2021; Yuan et al. 2021).

A major class of PRRs are the LRR-receptor kinases (RKs), including FLS2, EFR, and PEPR1/PEPR2, which recognize bacterial flagellin (flg22 epitope), elongation factor $\mathrm{Tu}$ (EF-Tu, elf18 epitope), and the endogenous Pep epitopes embedded in their precursors, PROPEPs, respectively (Gómez-Gómez and Boller 2000; Krol et al. 2010; Yamaguchi et al. 2006, 2010; Zipfel et al. 2006). Following ligand binding, these PRRs form heteromeric receptor complexes with the LRR-RK BAK1 (and related SERKs), then induce dissociation of receptor-like cytoplasmic kinases (RLCKs) such as BIK1 and PBL1. Their transphosphorylation provides a basis for intracellular defense signaling, which involves $\mathrm{Ca}^{2+}$ release and an RBOHDdependent reactive oxygen species (ROS) burst, phosphorylation cascades of $\mathrm{Ca}^{2+}$-dependent protein kinases and mitogenactivated protein kinases (MAPKs), callose deposition, production of the phytohormones ethylene and salicylic acid (SA), and extensive reprogramming of the transcriptome and proteome (Couto and Zipfel 2016; Saijo et al. 2018; Yu et al. 2017). These signaling events collectively contribute to PTI, and also provide possible internodes for balancing immunity and other cellular processes.

Activation of PTI is required to potentiate ETI for effective pathogen resistance (Ngou et al. 2021; Yuan et al. 2021). SA is a key for this process in biotrophic and hemibiotrophic pathogen resistance, and is produced in large part through the SA biosynthetic enzyme isochorismate synthase1 (ICS1) during PTI (Vlot et al. 2009; Wildermuth et al. 2001). SA signaling relies on the SA-binding transcriptional coactivator NPRI and corepressors NPR3 and NPR4 (Ding and Ding 2020), and also on EDS1 and related PAD4 (Wiermer et al. 2005). EDS1 and PAD4 activate ICS1 expression and SA accumulation but also promote ICS1and SA-independent defenses (Bartsch et al. 2006; Cui et al. 2017; Glazebrook et al. 2003). Accordingly, EDS1 is required for basal resistance to biotrophic and hemibiotrophic pathogens (Dongus and Parker 2021). However, excessive de-repression of EDS1- and PAD4-mediated defenses during osmotic stress results in a collapse of osmotic stress tolerance (Ariga et al. 2017). Therefore, tight control of EDS1 and PAD4 activity is crucial under not only biotic but also abiotic stress conditions.

Genetic studies have implicated PRRs in salt stress tolerance. In A. thaliana, ectopic expression of fungal chitinase or chitin application enhances salt tolerance in a manner dependent on the lysin-motif RK CERK1, which mediates the perception of fungal chitin and bacterial peptidoglycans (Brotman et al. 2012). Even under sterile conditions in the absence of microbes or MAMPs, cerkl plants are hypersensitive to salt stress (Espinoza et al. 2017). These studies suggest that CERK1 has a role in promoting salt stress tolerance, and that this function is related to as-yet-unidentified endogenous DAMPs. Likewise, PROPEP3 overexpression and Pep3 application under sterile conditions both enhance salt tolerance through PEPRI (Nakaminami et al. 2018). These studies suggest that DAMP sensing and signaling contribute to salt stress tolerance; however, the underling principles are not defined.

Here, we report that PTI signaling components promote salt tolerance in A. thaliana following recognition of various immunogenic patterns. Transcriptome profiling reveals an inventory of defense- or stress-related genes that increase or acquire salt responsiveness after PRR elicitation. Recognition of nonpathogenic bacteria also leads to salt tolerance through these PRR signaling components. Our findings indicate that immunogenic pattern sensing of cellular damage and plant-associated microbes is intimately linked to salt stress tolerance.

\section{RESULTS}

\section{Recognition of DAMPs and MAMPs leads to salt tolerance.}

Whole-genome microarray analysis for Pep2- and elf18induced transcriptional reprogramming in Arabidopsis seedlings (Ross et al. 2014) produced an inventory of Pep2- and elf18inducible genes ( $\geqq$ fourfold) (i.e., 575 and 76 genes with Pep2 at 2 and $10 \mathrm{~h}$, respectively, and 536 and 380 genes with elf 18 at 2 and $10 \mathrm{~h}$, respectively). In silico data analysis suggests that the majority of these PTI-inducible genes are also induced in seedling shoots or roots in response to salt and osmotic stresses (Supplementary Fig. S1A), as previously described for chitin (Espinoza et al. 2017). The common target genes included members of the PROPEP family and PEPR1/PEPR2 (Supplementary Fig. S1A), implying the extensive engagement of this DAMP pathway under salt stress. These data prompted us to examine whether recognition of different MAMPs and DAMPs leads to salt stress tolerance and, if so, by what mechanism.

We first tested whether pretreatment of seedlings with Pep, flg22, and elf18 peptides confers salt stress tolerance. Salt tolerance was determined as the ratio of viable (green) plants to dead or dying plants with bleached leaves, over the total number of the tested plants (Fig. 1A). In nonelicited plants, the survival rate declined to $36 \%$, whereas survival of Pep1-pretreated seedlings was 94\% 7 days after salt stress (Fig. 1B). Pep1-triggered salt stress was effective, at least up to $200 \mathrm{mM} \mathrm{NaCl}$ (Supplementary Fig. S1B). Pep1, Pep2, Pep3, and Pep4 pretreatments all significantly increased plant tolerance to $175 \mathrm{mM} \mathrm{NaCl}$ (Supplementary Fig. S1C; Table 1). Pep1 pretreatment resulted in increases in overall seedling fresh weight and chlorophyll contents (Fig. 1C and D), pointing to enhanced salt stress tolerance (Acosta-Motos et al. 2017). PEPR1 recognizes all Pep peptides while PEPR2 recognizes only Pep1 and Pep2 (Bartels et al. 2013; Krol et al. 2010). Although it was previously described that PEPR1 but not PEPR2 is required for Pep3-triggered salt tolerance (Nakaminami et al. 2018), our analysis showed that Pep1-triggered salt tolerance was retained in peprl or pepr 2 but abolished in peprl pepr2 plants (Fig. 1; Table 1). Accordingly, Pep1 
effects on shoot fresh weights and chlorophyll contents under salt stress were absent in pepr1 pepr2 plants (Fig. 1C and D). The results indicate that PEPR1 and PEPR2 both mediate salt tolerance, despite their differences in Pep ligand specificity.

PRR signaling activation under sterile conditions typically leads to growth retardation (Boller and Felix 2009). Conceivably, the lowered metabolic activity accompanying reduced growth could lower salt uptake into the plant, thereby conferring apparent tolerance. However, pepr 2 plants acquired salt tolerance following Pep1 application (Table 1), without discernible growth inhibition (Krol et al. 2010). Pep3 and Pep4 application also conferred salt tolerance without significantly inhibiting root growth (Supplementary Fig. S1C; Table 1). This indicates that plant
A
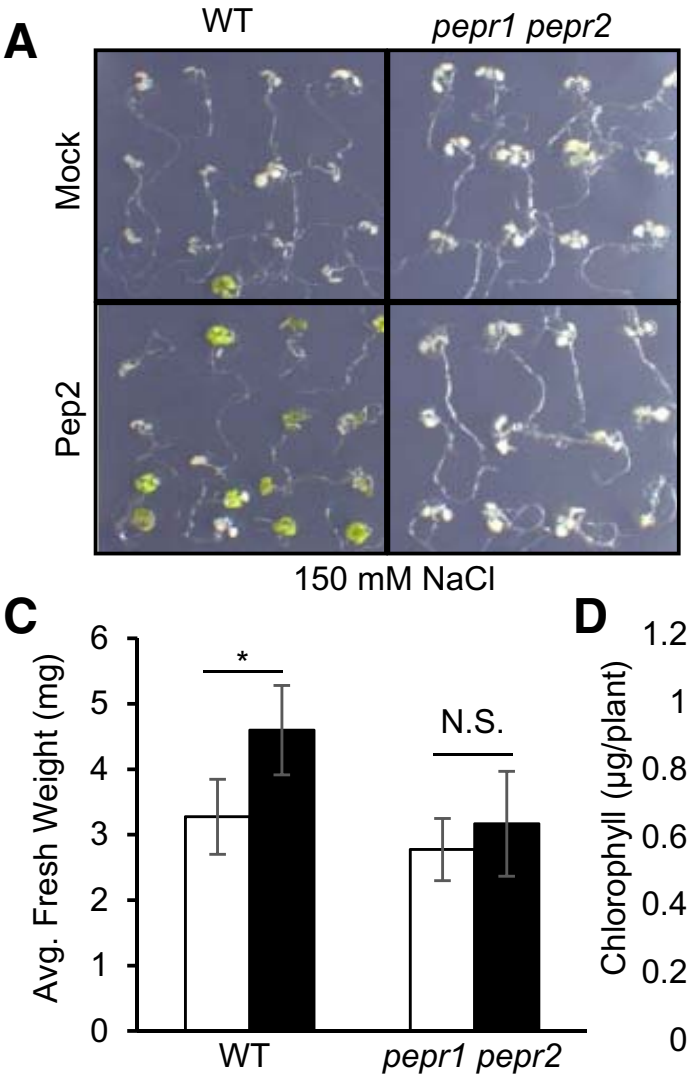

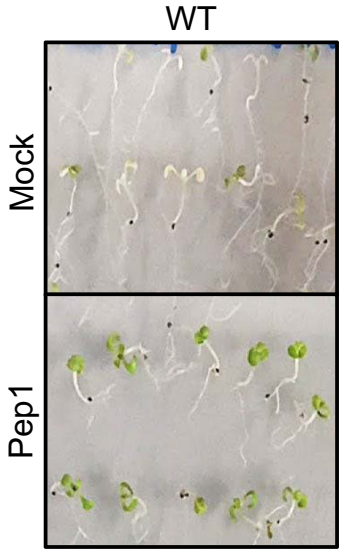

$175 \mathrm{mM} \mathrm{NaCl}$
B
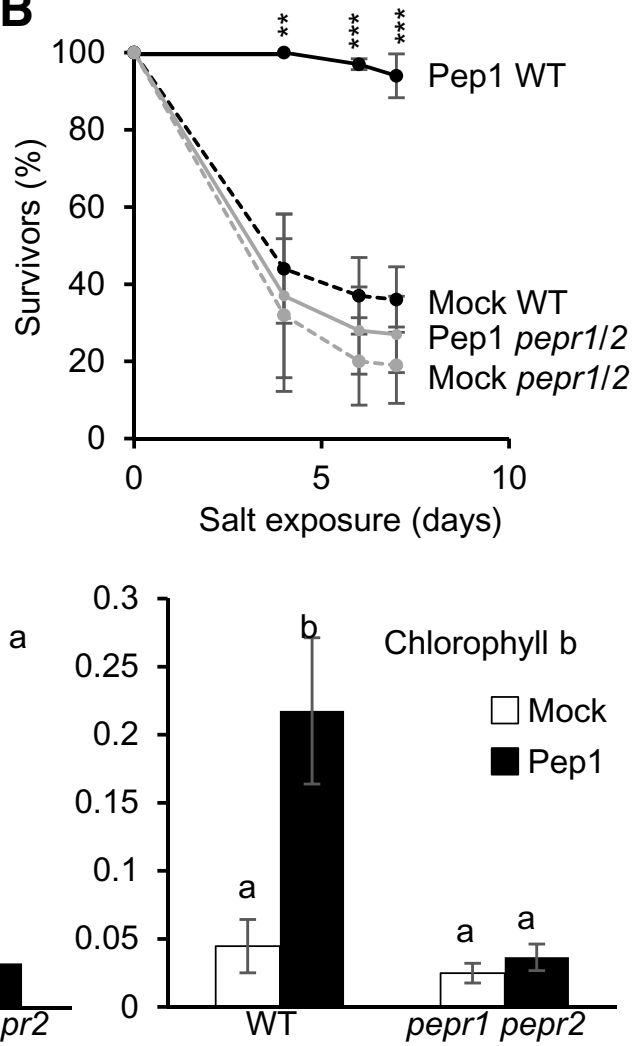

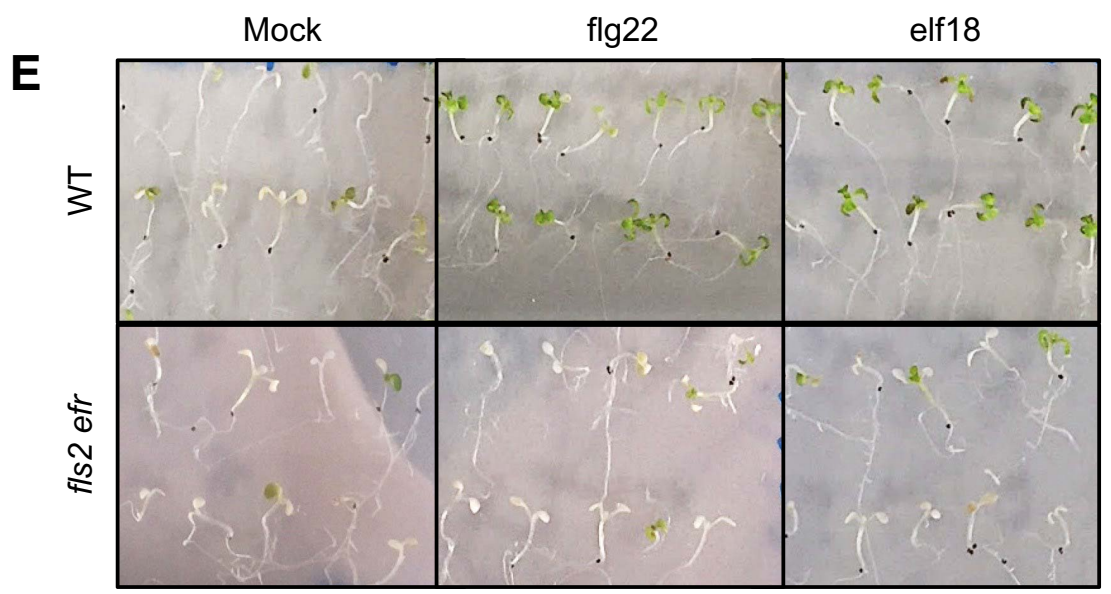

$\mathbf{F}$

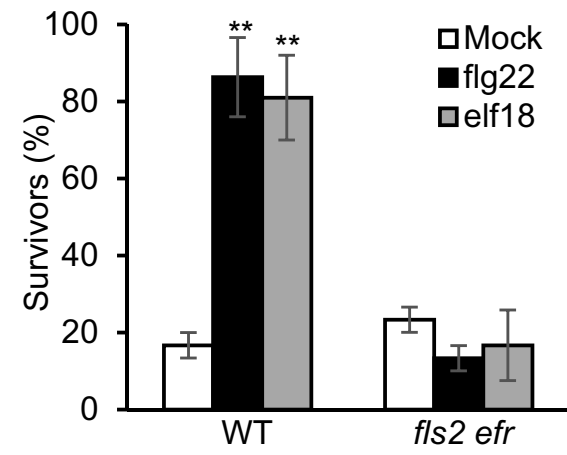

Fig. 1. Pattern recognition receptors confer salt stress tolerance in Arabidopsis thaliana following recognition of cognate damage-associated molecular patterns. A, Phenotype of A. thaliana seedlings after (left) 6 days of exposure to $150 \mathrm{mM} \mathrm{NaCl}$ and (right) 5 days of exposure to $175 \mathrm{mM} \mathrm{NaCl}$, with or without Pep2 or Pep1 pretreatments. B, Survival rate (mean \pm standard error of the mean [s.e.m.], $n \geq 50$, two replicates) of seedlings after their exposure to $150 \mathrm{mM} \mathrm{NaCl}$ for the indicated duration, with and without $0.1 \mu \mathrm{M}$ Pep1 pretreatment. Asterisks $* * *$ and $* *$ indicate $P<0.001$ and 0.01 , respectively, using two-tailed $t$ tests compared with the corresponding values of the mock-treated plants. C, Average fresh weights (mean \pm s.e.m., $n \geq 30$, four replicates) of seedlings after 5 days of exposure to $150 \mathrm{mM} \mathrm{NaCl}$, with and without $0.1 \mu \mathrm{M}$ Pep1 pretreatment. An asterisk (*) indicates $P<0.05$ using two-tailed $t$ tests compared with the corresponding values of the mock-treated plants; N.S. $=$ not significant. D, Chlorophyll contents (mean \pm s.e.m., $n \geq 30$, four replicates) in seedlings after 5 days of exposure to $150 \mathrm{mM} \mathrm{NaCl}$, with and without $0.1 \mu \mathrm{M}$ Pep 1 pretreatment. Letters above bars indicate $P<0.05$ using Tukey's honestly significant difference (HSD) tests. E, Phenotype of seedlings after 5 days of exposure to $175 \mathrm{mM}$ NaCl, with or without $0.1 \mu \mathrm{M}$ of flg22 or elf18 pretreatment. F, Survival rate (mean \pm s.e.m., $n \geq 20$, two replicates) of seedlings after 6 days of exposure to $175 \mathrm{mM}$ NaCl, with and without $0.1 \mu \mathrm{M}$ flg22 or elf18 pretreatment. Asterisks (**) indicate $P<0.01$ using Tukey's HSD tests compared with the value of mock-treated wild-type (WT) plants 
growth inhibition is not required for pattern-triggered salt tolerance (PTST).

Importantly, pretreatment with flg22 or elf18 also conferred salt tolerance through cognate PRRs (Fig. 1E and F; Supplementary Fig. S1D). The results indicate that PTST is not specific to an immunogenic pattern or receptor but is common to a broad range of MAMPs and DAMPs. This is consistent with the view established in plant immunity that a wide array of PRRs link the recognition of diverse cognate ligands to a largely overlapping set of defense outputs (Saijo et al. 2018). The ligand dose dependence of flg22-induced salt tolerance was comparable with that of other flg22-induced outputs (Supplementary Fig. S1D) (Aslam et al. 2009; Gómez-Gómez et al. 1999). These results suggest that PTST shares postrecognition signaling mechanisms with PTI across different PRR pathways. Notably, chitin application did not affect salt tolerance under our conditions, despite significant induction of a defense marker, $C Y P 71 A 13$, encoding cytochrome P450 involved in camalexin biosynthesis (Supplementary Fig. S1E).

\section{Pattern-triggered salt tolerance and pattern-triggered immunity share early signaling steps downstream of the receptor.}

A major branch of PTI signaling triggered by the LRR-domain PRRs occurs through the receptor complexes with BAK1 and BIK1/PBL1 (Couto and Zipfel 2016). To test possible BAK1 dependence of PTST, we examined Pep1-triggered salt tolerance in a null bakl-4 allele and a hypoactive bakl-5 allele specifically impaired in PRR-related BAK1 function (Roux et al. 2011; Schwessinger et al. 2011). We previously described retention of PEPR-mediated defenses in bakl null mutants, reflecting PEPR1 interactions with other BAK1-related RKs (Yamada et al. 2016). Consistently, Pep1-induced salt tolerance was unaffected in bakl4 (Fig. 2). However, it was severely compromised in bakl-5 plants and bakl-5 bkkl plants that additionally lack BAK1-related RK $B K K 1$, required for PEPR-mediated defenses (Yamada et al. 2016) (Fig. 2). Likewise, Pep1-induced salt tolerance was also impaired in bikl pbll plants (Fig. 2). The results indicate that PTST signaling also occurs through these BAK1-related RKs and RLCKs.

Interestingly, seedling survival rate was also significantly lowered in bakl-5, bakl-5 bkkl, and bikl pbll plants when exposed to salt stress without exogenous Pep1 pretreatment (Fig. 2, mock controls), pointing to engagement of these PRR-associated kinases in salt tolerance. Our data suggest that the authentic receptor complexes mediate PTST, and that DAMPs or endogenous ligands generated under salt stress signal via $B A K 1 / B I K 1-$ dependent PRRs or receptors.

Pep1-triggered salt tolerance was reduced in rbohd plants lacking the PRR-associated NADPH oxidase responsible for a pattern-induced ROS burst (Fig. 2) (Kadota et al. 2015), pointing to a critical role also for this PRR output in PTST. By contrast, callose synthase PMR4/GSL5 mediating callose deposition during PTI (Kim et al. 2005) was not required for Pep1-triggered salt tolerance (Fig. 2), demonstrating that PRR-induced callose deposition is dispensable for PTST.

FLS2-mediated salt tolerance was also reduced in bak1-5 plants, indicated by decreases in the survival rate, seedling fresh weight, and chlorophyll contents under salt stress after flg22 pretreatment (Fig. 3A to C). It was also reduced in bakl-4 plants, indicated by chlorophyll contents (Fig. 3C), although the survival rate or seedling fresh weight was not significantly reduced (Fig. 3A and B). The partial retention of PTST may be attributed to a $B A K 1$-independent pathway mobilized by residual FLS2 signaling in the mutant. Nevertheless, the results indicate that PTST through these LRR-RKs relies on the PRR-regulating $B A K 1$ function, and that early signaling steps within and proximal to the PRR complexes, if not all, are shared between PTI and PTST.

\section{Pattern-triggered salt tolerance is robust against hormone perturbations.}

PRR signaling involves complex networks of defense-related hormones, including SA, jasmonic acid (JA) and ethylene in PTI (Pieterse et al. 2012). FLS2- and EFR-triggered immunity largely collapses in the simultaneous absence of $D D E 2$ encoding allene oxide synthase required for JA biosynthesis, EIN2 encoding the master regulator of ethylene signaling, SID2 (ICS1), and PAD4 (Tsuda et al. 2009). However, in dde2 ein2 pad4 sid2 plants, PTST was unaffected (Supplementary Fig. S2A), indicating that these defense-related sectors are all dispensable for PTST.

We also assessed whether PTST is dependent on abscisic acid (ABA), which is central to plant adaptation to salt, osmotic, and water-deficit stresses (Cutler et al. 2010; Finkelstein 2013). PTST was unaffected in aba2-12 plants impaired in ABA biosynthesis (González-Guzmán et al. 2002) and in areb1 areb2 $a b f 3$ plants lacking key transcription factors mediating ABA responses (Yoshida et al. 2015) (Supplementary Figs. S2B and C), suggesting that ABA is also dispensable for PTST. Overall, our findings point to high PTST robustness against perturbations of these biotic and abiotic stress-related hormone pathways.

\section{Salt-induced damage sensing and signaling involves the Pep-PEPR pathway.}

To test involvement of endogenous DAMPs in salt tolerance, we monitored endogenous PROPEP-PEPR signaling under salt stress. Given the substantial induction of PROPEPS and PEPRI/ $P E P R 2$ in roots (Supplementary Fig. S1A), we examined PROPEP3 protein expression in the roots of transgenic plants expressing PROPEP3-Venus under its native regulatory DNA sequences. A strong PROPEP3-Venus fluorescence signal was

Table 1. PEPR1 and PEPR2 both contribute to Pep-induced salt tolerance in Arabidopsis thaliana

\begin{tabular}{|c|c|c|c|c|c|c|}
\hline \multirow[b]{2}{*}{ Genotype } & \multirow[b]{2}{*}{ Pretreatment } & \multirow[b]{2}{*}{ Survivors } & \multirow[b]{2}{*}{ Total seedlings } & \multirow[b]{2}{*}{ Survival $(\%)^{\mathbf{a}}$} & \multicolumn{2}{|c|}{ Fisher's test } \\
\hline & & & & & $\overline{\text { Versus WT }}$ & $\overline{\text { Versus mock }}$ \\
\hline \multirow[t]{6}{*}{ Wild type } & Mock & 5 & 30 & 16.6 & - & - \\
\hline & Pep1 & 29 & 30 & 96.7 & - & $P<0.01$ \\
\hline & Pep3 & 30 & 46 & 65.2 & - & $P<0.01$ \\
\hline & Pep4 & 40 & 50 & 80 & - & $P<0.01$ \\
\hline & Mock & 6 & 136 & 4.4 & - & - \\
\hline & Pep2 & 87 & 140 & 62.1 & - & $P<0.01$ \\
\hline \multirow[t]{2}{*}{ peprl } & Mock & 5 & 35 & 14.3 & - & - \\
\hline & Pep1 & 26 & 30 & 86.7 & N.S. & $P<0.01$ \\
\hline \multirow[t]{2}{*}{ pepr 2} & Mock & 1 & 30 & 3.3 & - & - \\
\hline & Pep1 & 30 & 30 & 100 & N.S. & $P<0.01$ \\
\hline
\end{tabular}

\footnotetext{
${ }^{\text {a }}$ Survival rate (\%) of seedlings 7 days after exposure to $175 \mathrm{mM} \mathrm{NaCl}$. N.S. = not significant.
} 
detected $24 \mathrm{~h}$ after salt stress but not under mock conditions (Fig. 4A). Damage-induced release of PROPEP1 from the vacuole and that of PROPEP3 to extracellular spaces (Hander et al. 2019; Yamada et al. 2016) prompted us to test for possible PROPEP release under salt stress. We traced PROPEP3-Venus accumulation in the surrounding liquid media, following salt stress or Pep1 application. Immunoblot analysis with PROPEP3specific antibodies (Ross et al. 2014) detected specific signals that were close to the predicted full-length size of PROPEP3-Venus (approximately $10.4+27 \mathrm{kDa}$ ) (Yamada et al. 2016) following Pep1 application (Fig. 4B), as described for Pep2 application (Yamada et al. 2016). Apparently, shorter forms of PROPEP3Venus were additionally detected under salt stress with or without
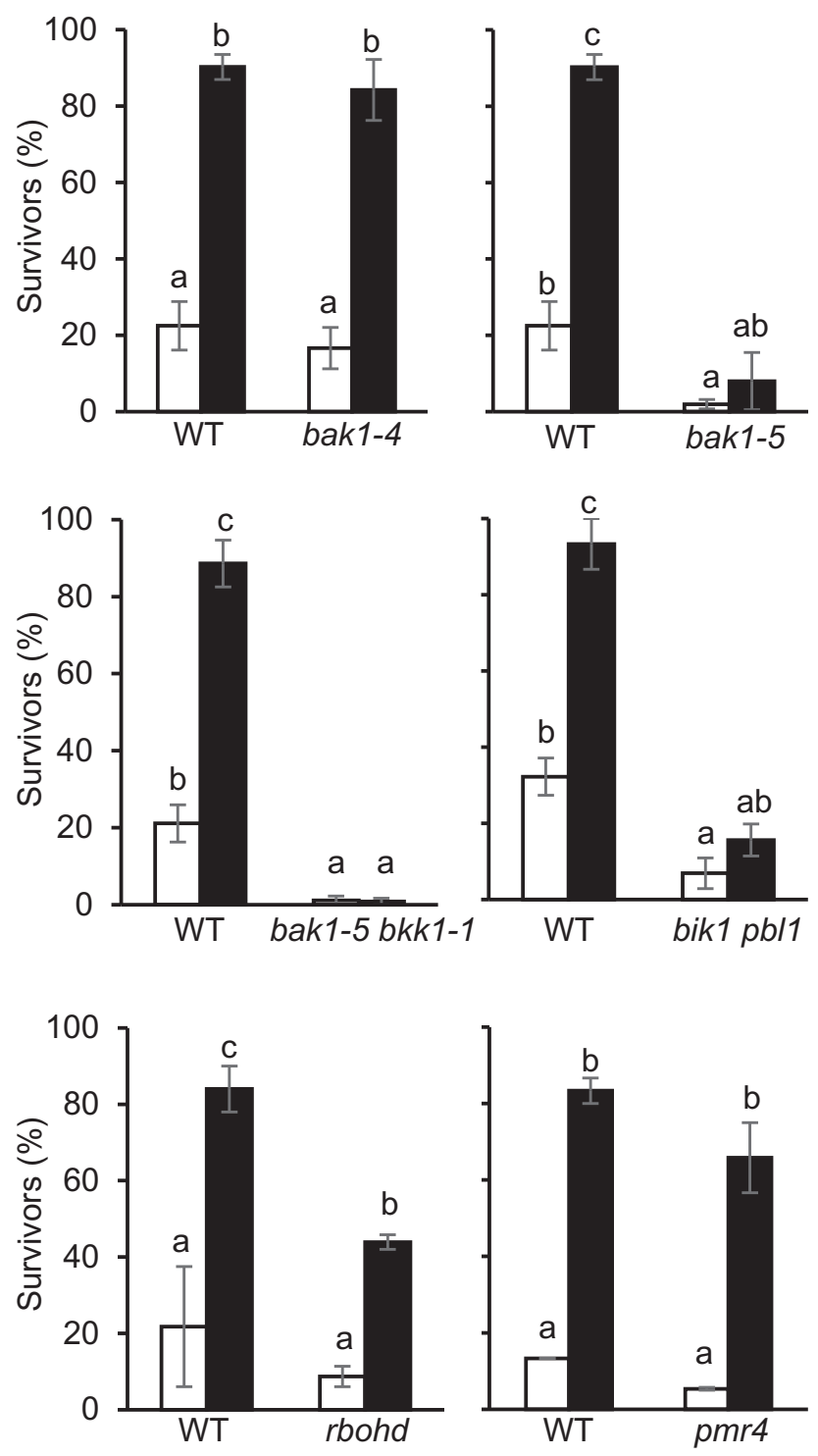

$\square$ Mock

Pep1

Fig. 2. Genetic requirements for pattern-triggered immunity signaling components in pattern-triggered salt tolerance. Survival rate (mean \pm standard error of the mean, three replicates unless otherwise stated) of seedlings pretreated with $0.1 \mu \mathrm{M}$ Pep1/flg22, determined after their exposure to $175 \mathrm{mM} \mathrm{NaCl}$ for the indicated durations: bakl-4 and bakl-5, 9 days $(n \geq 20)$; bakl-5 bkkl-1, 8 days $(n \geq 30)$; bikl pbll, 5 days $(n \geq 25)$; rbohd, 8 days $(n \geq 30)$; and pmr4, 6 days $(n \geq 30$, two replicates). WT $=$ wild type. Letters above bars indicate $P<0.05$ using Tukey's honestly significant difference tests.
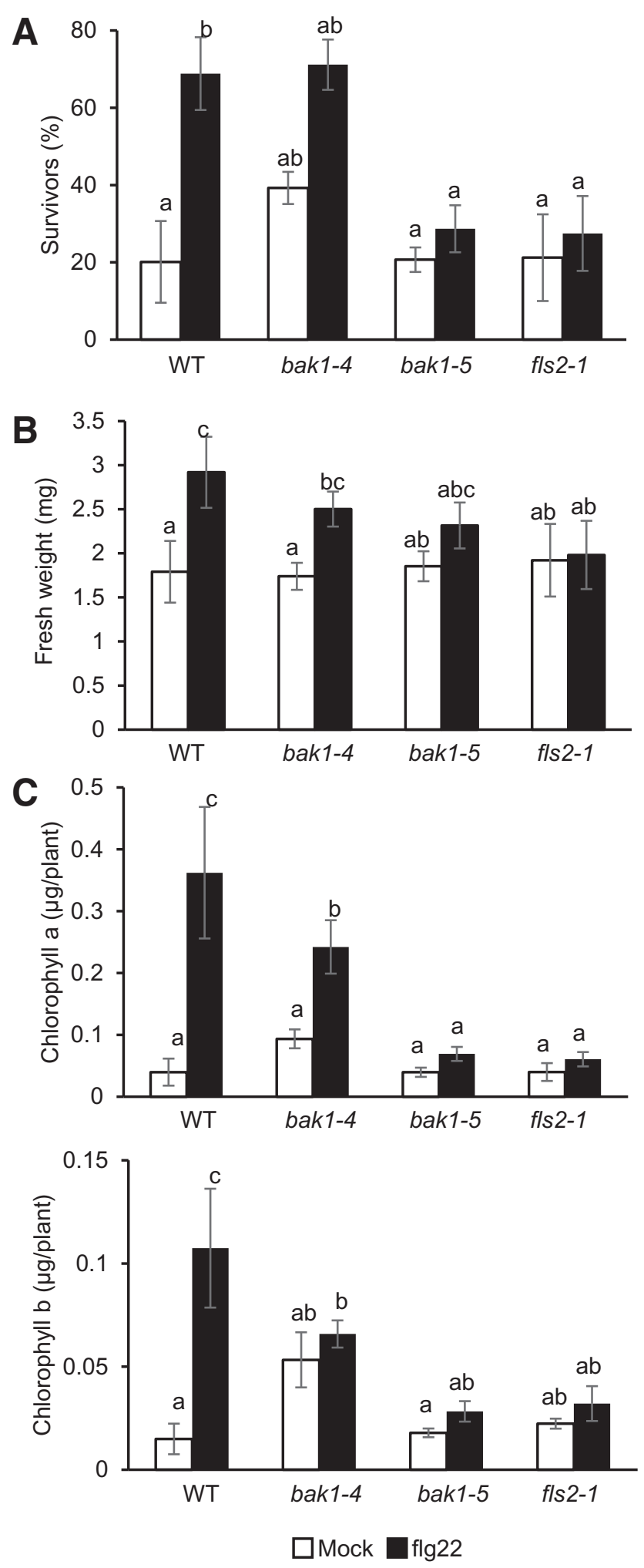

Fig. 3. Recognition of bacterial microbe-associated molecular patterns by cognate pattern recognition receptors confers salt tolerance in a manner dependent on $B A K 1$ and $B I K 1$. WT $=$ wild type. A, Survival rate (mean \pm standard error of the mean [s.e.m.]) seedlings after 7 days $(n \geq$ 34 , three replicates) of exposure to $150 \mathrm{mM} \mathrm{NaCl}$, with and without $0.1 \mu \mathrm{M}$ flg22 pretreatment. B, Average fresh weights (mean \pm s.e.m., $n \geq$ 10 , three replicates) of seedlings after 7 days of exposure to $150 \mathrm{mM}$ $\mathrm{NaCl}$, with and without $0.1 \mu \mathrm{M}$ flg22 pretreatment. C, Chlorophyll contents (mean \pm s.e.m., $n \geq 10$, three replicates) in seedlings after 7 days of exposure to $150 \mathrm{mM} \mathrm{NaCl}$, with and without $0.1 \mu \mathrm{M}$ flg22 pretreatment. Letters above bars indicate $P<0.05$ using Tukey's honestly significant difference tests. 


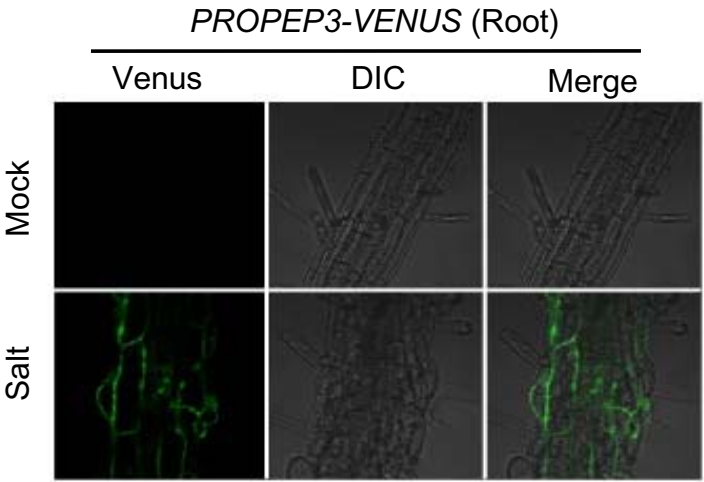

B
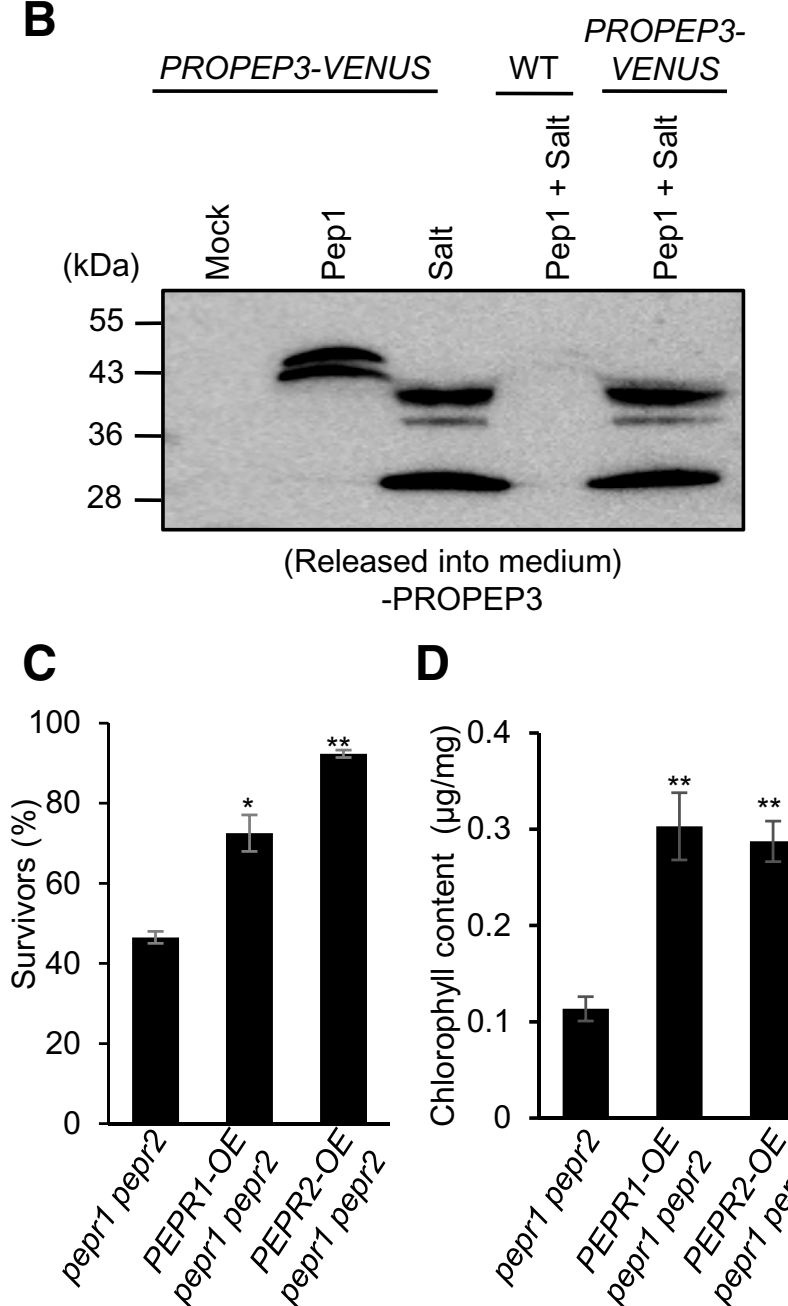

D

Fig. 4. Endogenous PROPEP-PEPR signaling is activated under salt stress. A, Live cell imaging of pPROPEP3::PROPEP3-VENUS in Arabidopsis thaliana roots under $150 \mathrm{mM} \mathrm{NaCl}$ for $24 \mathrm{~h}$. B, Immunoblot analysis for extracellular fractions (growth media) of PROPEP3-VENUS seedlings exposed to $0.5 \mu \mathrm{M}$ Pep1, $150 \mathrm{mM} \mathrm{NaCl}$, or combinations thereof. WT $=$ wild type. Positions of the molecular mass markers are shown on the left. Experiments were repeated twice with the same conclusions. C, Survival rate (mean \pm standard error of the mean [s.e.m.], $n \geq 20$, two replicates) of seedlings after 4 days of exposure to $175 \mathrm{mM}$ $\mathrm{NaCl}$, without microbe- or damage-associated molecular pattern pretreatment. Asterisks $(* *$ and $*$ ) indicate $P<0.01$ and 0.05 , respectively, using Tukey's honestly significant difference (HSD) compared with the values of peprl pepr 2 plants. D, Chlorophyll contents (mean \pm s.e.m., four replicates) in seedlings after 14 days of exposure to $750 \mathrm{mM}$ sorbitol following 7 days of pretreatment with $100 \mathrm{mM} \mathrm{NaCl}$. Asterisks (**) indicate $P<0.01$ using Tukey's HSD tests.
Pep1 application (Fig. 4B), possibly reflecting PROPEP3 processing that may occur in the intracellular or extracellular spaces. Under these conditions, endogenous PROPEP3-derived signals were not detected. Nevertheless, these results validate that PROPEP3 is released under salt stress.

To assess a possible contribution of the endogenous PEPR pathway to salt tolerance, we examined salt responses of PEPR1 and PEPR2 overexpressing lines (PEPR1-OE or PEPR2-OE, respectively) in the peprl pepr2 background, without exogenous application of Peps or MAMPs. PEPRI-OE and PEPR2-OE plants both exhibited increased survival rates when exposed to $175 \mathrm{mM} \mathrm{NaCl}$ compared with that of peprl pepr 2 plants (Fig. 4C). Moreover, following 7 days of acclimatization to mild salt stress $(100 \mathrm{mM} \mathrm{NaCl})$, PEPRI-OE and PEPR2-OE plants acquired enhanced tolerance to severe osmotic stress (750 $\mathrm{mM}$ sorbitol) compared with pepr1 pepr 2 plants, indicated by the leaf chlorophyll contents (Fig. 4D). These data provide compelling evidence that an endogenous PEPR pathway contributes to salt and osmotic stress tolerance, in the absence of exogenous Pep application. Collectively, the results indicate that salt stress induces the generation and release of PROPEP-derived peptides, which engages PEPR signaling in salt or osmotic stress tolerance.

\section{Pep1 pretreatment strengthens transcriptome dynamics in response to salt stress.}

To gain a mechanistic insight into PTST, we performed transcriptome profiling on wild-type (WT) and peprl pepr2 plants during the course of PTST. To capture useful information from the salt-sensitive samples, plants were subjected to $150 \mathrm{mM}$ $\mathrm{NaCl}$ after Pep1 application. Because salt-induced transcriptional reprogramming is largely achieved within the first $24 \mathrm{~h}$ (Geng et al. 2013), we obtained the data under salt stress for 3 and 24 h, after a 3-day Pep1 pretreatment (Fig. 5A). Up- or downregulated genes under salt stress in nonelicited plants (mock), with a cut-off of $\mid \log _{2}$ (fold change) $\mid \geqq 1(P<0.05)$, were assembled at the indicated times, defining the salt-responsive differentially expressed genes (DEGs) (Fig. 5B). Likewise, genes whose expression was significantly altered, both between Pep1- and mock-pretreated WT plants and between Pep1-pretreated WT plants and peprl pepr 2 plants, were assembled at the indicated times under salt stress, defining PTST-DEGs (exhibiting Pep1/ PEPR-dependent alterations in salt responsiveness) (Fig. 5B). DEGs were scored at the earliest time points when their expression levels first met these criteria.

In nonelicited plants under salt stress, we detected, in total, 1,285 up- versus 911 downregulated DEGs and 1,497 up- versus 1,363 downregulated DEGs at 3 and $24 \mathrm{~h}$, respectively (Fig. 5B). This suggests that salt-induced transcriptional reprogramming persisted over the tested time window. In Pep1-pretreated plants, we detected 639 up- versus 416 downregulated PTST-DEGs 3 $\mathrm{h}$ after salt stress but merely 32 up- versus 315 downregulated PTST-DEGs at $24 \mathrm{~h}$ (Fig. 5B). This suggests that PRR signaling particularly impacts the early responsiveness of salt-inducible genes.

Next, we examined possible overlap and divergence between the obtained salt-inducible DEGs and the previously described Pep2- or elf18-responsive DEGs (2 and 10 h) (Ross et al. 2014). This showed that 599 genes $(34.1 \%$ of Pep2/elf18-inducible genes and $22.9 \%$ of salt-inducible genes) were commonly induced between the two types of stimuli, while 1,155 and 2,012 genes were specifically induced in response to Pep2/elf18 and salt stress, respectively (Fig. 5C). Our analysis indicates a substantial overlap but also a clear separation in the transcriptome between the biotic and abiotic stresses, in which a large portion of pattern-responsive genes is inherently not responsive to salt stress and vice versa. 
A
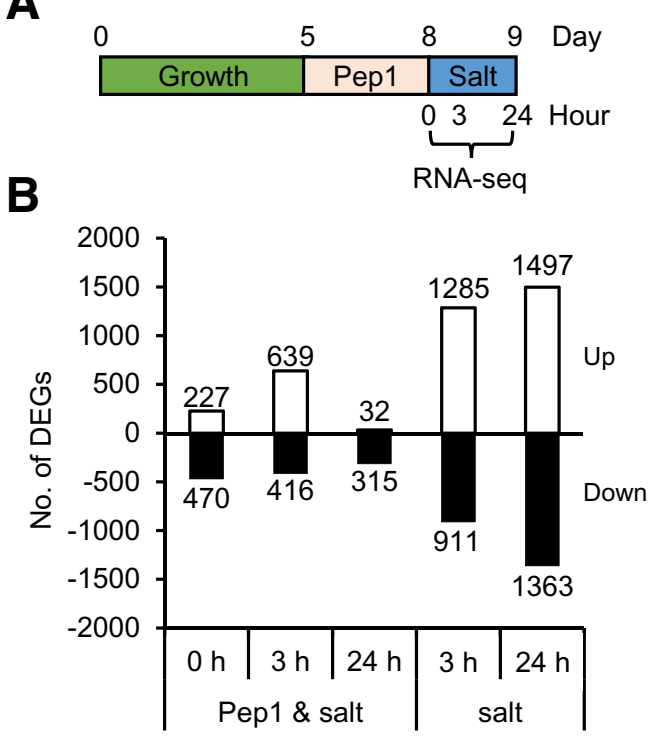

C
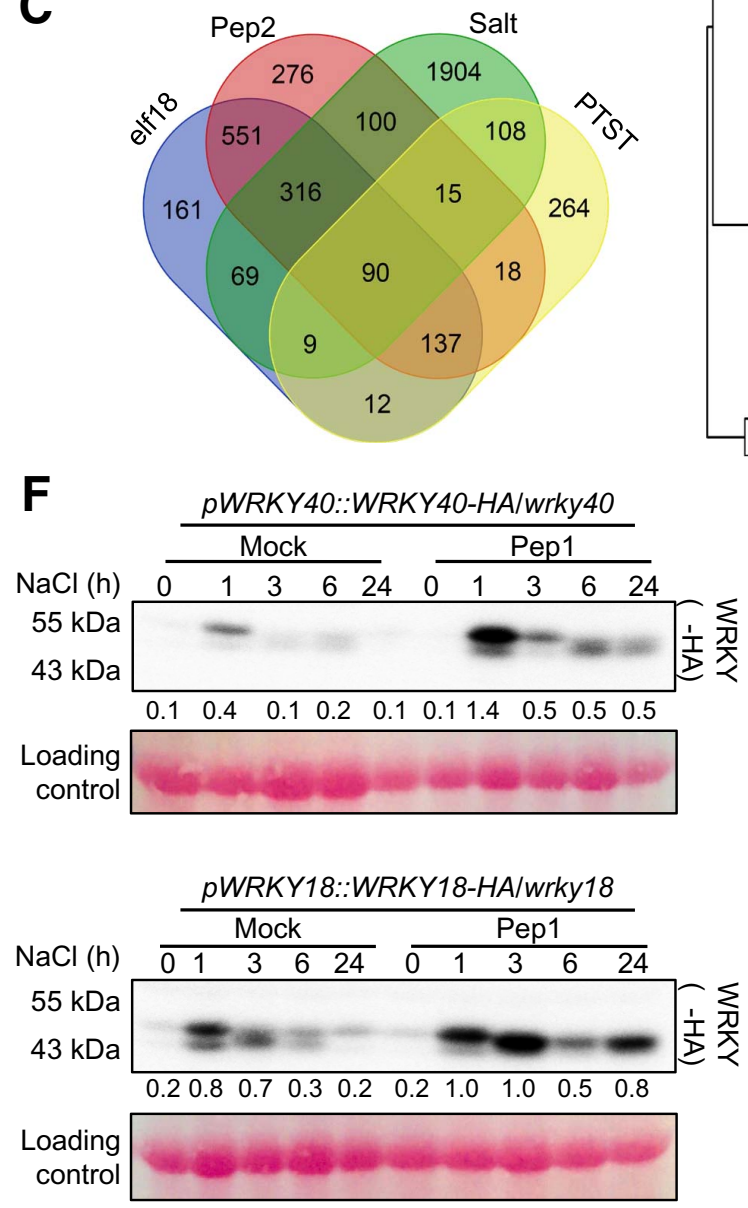
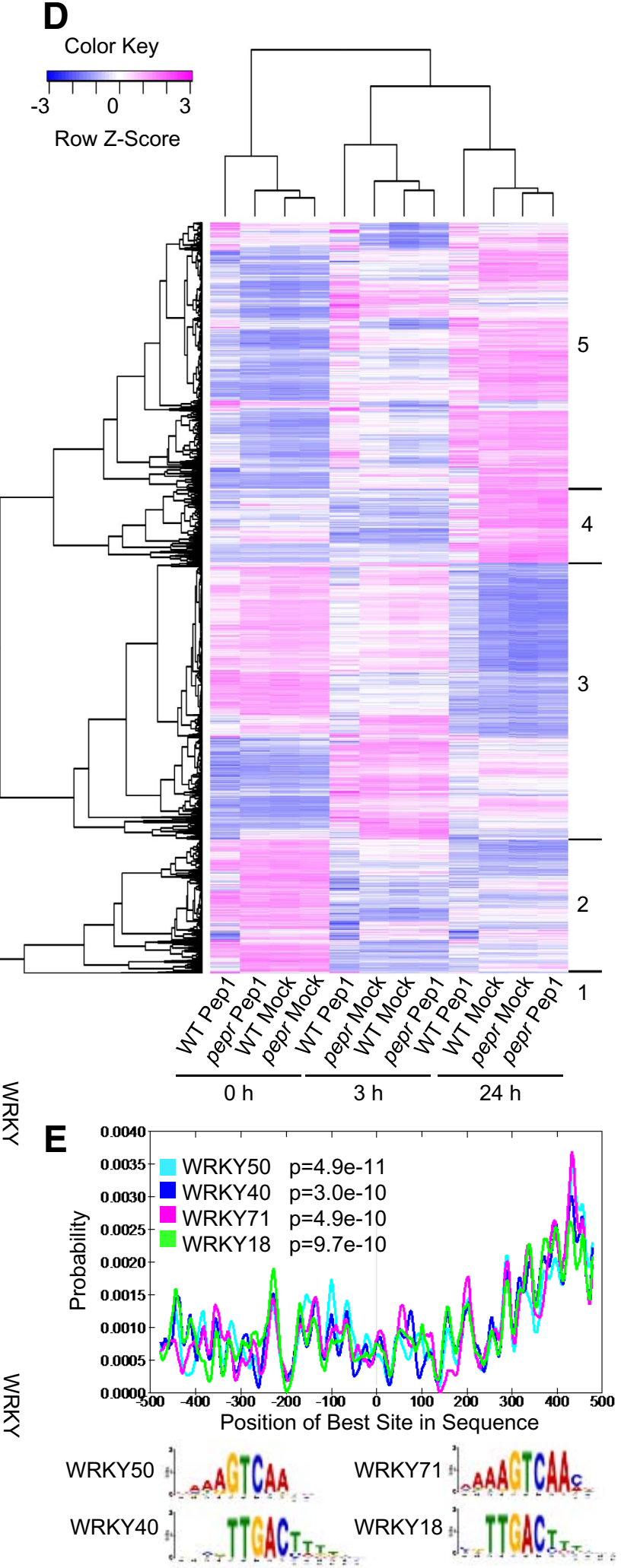

Fig. 5. Rapid and heightened activation of salt-induced transcriptional reprogramming during pattern-triggered salt tolerance (PTST). A, Scheme of PTST assay for RNA sequencing analysis. B, Number of Pep1- or salt-induced differentially expressed genes (DEGs) after exposure of seedlings to $150 \mathrm{mM} \mathrm{NaCl}$ for the indicated durations. C, Venn diagram illustrating the overlap between elf18-, Pep2-, salt-, and Pep1-PTST-inducible DEGs. Numerals represent the numbers of the genes. D, Heatmap depicting salt-DEGs and Pep1-PTST DEGs using one minus Pearson correlation complete linkage hierarchical clustering. WT = wild type. E, Cis-element enrichment analysis with CentriMo for the regulatory DNA sequences within $1 \mathrm{~kb}$ (from $500 \mathrm{correspond}$ ing to the transcription starting sites to -500 on the X-axis) upstream of 343 genes in the cluster 5, whose salt induction was sensitized following Pep1 pretreatment. Results for the most overrepresented four transcription factors are shown. F, Immunoblot analysis for 9-day-old seedlings exposed to $175 \mathrm{mM}$ $\mathrm{NaCl}$ for the indicated times following $0.1 \mu \mathrm{M}$ Pep1 pretreatment. Positions of the molecular weight markers (left) and Ponceau S-stained loading controls (bottom) are shown. Experiments were repeated three times with the same conclusions. Numerals below the immunoblots indicate the band intensities relative to that of the corresponding loading control in the representative blots. 
Of 1,754 elf18- or Pep2-inducible DEGs and 2,611 saltinducible DEGs, 281 genes (16.0\%) and 222 genes (8.5\%), respectively, were defined as PTST-DEGs (Fig. 5C). Notably, these included pattern-specific DEGs which acquired salt inducibility following Pep1 pretreatment but were otherwise not responsive to salt stress: a 3-day Pep1 pretreatment rendered 164 genes $(125+39$ genes in Supplementary Fig. S3A, relative to 1,285 genes, inherently salt-inducible) significantly induced at $3 \mathrm{~h}$ after salt stress, and 24 genes $(13+11$ genes in Supplementary Fig. S3A, relative to 2,251 genes, inherently salt-inducible) at $24 \mathrm{~h}$ after salt stress. Moreover, PTST-DEGs included 264 genes, which were not among the elf18/Pep2-DEGs or saltDEGs but acquired salt inducibility in Pep1-pretreated plants (Fig. 5C). These results indicate that preactivation of PRR signaling not only sensitizes salt stress responses but also broadens the range of target genes in salt stress responses, and emphasize that these effects are prominent early in salt responses.

We further dissected all of the salt- and PTST-DEGs (Fig. 5B) by hierarchical clustering. The genes were classified into five clusters (Fig. 5D; Supplementary Table S1). Gene ontology (GO) analyses revealed no significant GO term enrichment for cluster 1, presumably due to the low number of genes (20 genes; Supplementary Table S1). Clusters 2, 3, 4, and 5 were overrepresented with lipid localization. Lipid is among the major components of the plasma membranes that are important not only for membrane remodeling (i.e., adjusting membrane fluidity and permeability during salt stress) but also for numerous lipid signalings involved in the adaptation to salt and osmotic stress (Guo et al. 2019; Hou et al. 2016). Cluster 3 was also overrepresented with negative regulation of photosynthesis, consistent with the reduction of chlorophyll contents in the absence of Pep1-triggered salt tolerance (Figs. 1E and 3F). Cluster 4 was also overrepresented with negative regulation of root development, a hallmark response under salt stress (Acosta-Motos et al. 2017).

Notably, cluster 5 (2,194 genes) was overrepresented with genes whose salt induction at $3 \mathrm{~h}$ was increased after Pep1 pretreatment (Fig. 5D). It included a set of genes related to both defense and salt stress responses. For example, PTR3, encoding a putative peptide transporter, promotes both salt tolerance during seed germination and basal resistance to $P$. syringae pv. tomato DC3000 (Karim et al. 2005, 2007). SnRK2.8 encodes an osmotic stress-activated protein kinase, which promotes drought tolerance (Umezawa et al. 2004) and systemic immunity by phosphorylating NPR1 (Lee et al. 2015). Interestingly, BON1 that negatively regulates cell death but positively regulates osmotic stress tolerance (K. Chen et al. 2020) was found in this cluster. Thus, it seems likely that PRR signaling preactivation leads to faster establishment of a salt-stress-adapted transcriptome during PTST.

\section{Transcriptional reprogramming during PTST.}

We then assembled salt-inducible genes that exhibited rapid induction following Pep1 pretreatment. Of the cluster 5 genes, 343 genes increased their salt induction at $3 \mathrm{~h}$ in Pep1pretreated plants, while their induction was higher at 24 than at $3 \mathrm{~h}$ in nontreated plants (Supplementary Fig. S3B). In their regulatory DNA sequences, within $1,000 \mathrm{bp}$ upstream of the transcriptional start sites, a motif enrichment analysis (CentriMo) (Bailey and Machanick 2012) revealed overrepresentation of the $\mathrm{W}$ box-containing sequences (58 of 59 overrepresented transcription factor binding sites) (Supplementary Table S2). Four best-represented motifs were all prominent in the proximity to the transcription starting sites and included WRKY18- and WRKY40-specific DNA binding motifs (Fig. 5E; Supplementary Table S2), pointing to direct transcriptional regulation of these genes by WRKY18 and WRKY40 during PTST. WRKY18 and
WRKY40 negatively regulate flg22 induction of defense-related genes during PTI (Birkenbihl et al. 2017). Interestingly, WRKY18 and WRKY4O target genes (Birkenbihl et al. 2017) were more clearly enriched in cluster 5 genes displaying faster induction (149 of 329 loci) compared with all cluster 5 genes (471 of 2,083 loci) or PTST-DEGs (720 of 5,844 loci) (Supplementary Fig. S3C), pointing to their role in rapid activation of a salt-induced transcriptome.

To test how WRKY18 and WRKY40 are regulated during PTST, we conducted immunoblot analyses of functional HA-tagged WRKY18 and WRKY40 proteins expressed under the control of their native regulatory DNA sequences ( $p$ WRKY18::WRKY18$H A$ wrky 18 and $p W R K Y 40:: W R K Y 40-H A$ wrky40, respectively) (Birkenbihl et al. 2017). WRKY18 and WRKY40 accumulation was shown to be rapidly induced in response to flg22, with a peak of protein abundance at $1.5 \mathrm{~h}$ (Birkenbihl et al. 2017). WRKY18 and WRKY40 accumulation was reduced to nearly background levels 4 days after Pep1 application $(0 \mathrm{~h} \mathrm{NaCl})$ (Fig. 5F). WRKY40-HA accumulation became strongly induced $1 \mathrm{~h}$ after salt stress, and then diminished (Fig. 5F), indicating that there is transient WRKY40 induction during PTI and salt stress. Importantly, Pep1 pretreatment markedly elevated and prolonged salt-induced WRKY40-HA accumulation up to $24 \mathrm{~h}$ (Fig. 5F), following its increased mRNA expression (Supplementary Fig. S3D). A similar Pep1 effect was observed for WRKY18-HA accumulation (Fig. 5F). These results suggest that PRR signaling preactivation leads to enhanced and durable accumulation of both WRKY40 and WRKY18 under salt stress.

In contrast to cluster 5 , cluster 4 was characterized by saltinducible genes at $24 \mathrm{~h}$, whose induction was suppressed after Pep1 pretreatment (Supplementary Fig. S4). Without PTST, their induction was prominent at 24 compared with $3 \mathrm{~h}$, and may reflect salt stress symptoms rather than salt stress tolerance. A motif enrichment analysis in their regulatory DNA sequences as described above revealed overrepresentation of three transcription factor binding motifs (namely, WRKY31, ANAC047, and WRKY20) (Supplementary Fig. S4; Supplementary Table S1), implying that Pep1 sensitization and Pep1 desensitization of salt-inducible genes occur through distinct sets of transcription factors. Although ANACO47 has been implicated in waterlogging responses and leaf senescence (Rauf et al. 2013), the other two have been poorly characterized to date.

\section{Nonpathogenic bacteria confer PTST.}

Because bacterial MAMP application confers salt tolerance (Fig. 3), we tested whether immune recognition of bacteria also leads to salt tolerance. To this end, we determined the effects of preinoculation with different strains of $P$. syringae pv. tomato DC3000 on salt stress tolerance: strain DC3000 $\Delta h r p S$, impaired in the expression of the type III effectors (Hutcheson et al. 2001) and conventionally used as a PTI trigger, and strain DC3000 AvrRpml or AvrRps4, inducing ETI conferred by the CC-NLR RPM1 and the TIR-NLR pair RRS1-S/RPS4, respectively (Gassmann et al. 1999; Grant et al. 1995; Saucet et al. 2015). All of these bacterial strains fail to grow in the WT plants used here, which harbor the cognate NLRs. Preinoculation with $P$. syringae pv. tomato DC3000 $\Delta h r p S$ significantly enhanced the survival rate of seedlings under salt stress, whereas strain DC3000 AvrRpml or strain DC3000 AvrRps4 did not (Fig. 6A). Without salt stress, plant survival rates were essentially indistinguishable between these nonpathogenic and avirulent strains (Supplementary Table S2). These results suggest that PRR recognition but not NLR recognition of live bacteria effectively confers salt tolerance.

Notably, bacterium-triggered salt tolerance was strongly reduced in the PRR mutants and PRR-associated kinase mutants 
fls2 efr and bakl-5 bkkl-1, respectively (Fig. 6B and C), as in MAMP- or DAMP-triggered salt tolerance (Figs. 1, 2, and 3). Basal salt tolerance under sterile conditions (in mock controls without bacteria) was significantly lowered in bakl bkkl plants but was unaffected in $f l s 2$ efr plants (Fig. 6B and C), pointing to involvement of one or more $B A K 1$-dependent DAMP receptors but not MAMP receptors FLS2 or EFR in basal salt tolerance. Preinoculation with nonpathogenic PTI-triggering bacterium P. simiae WCS417 (P. fluorescence) also conferred salt tolerance,
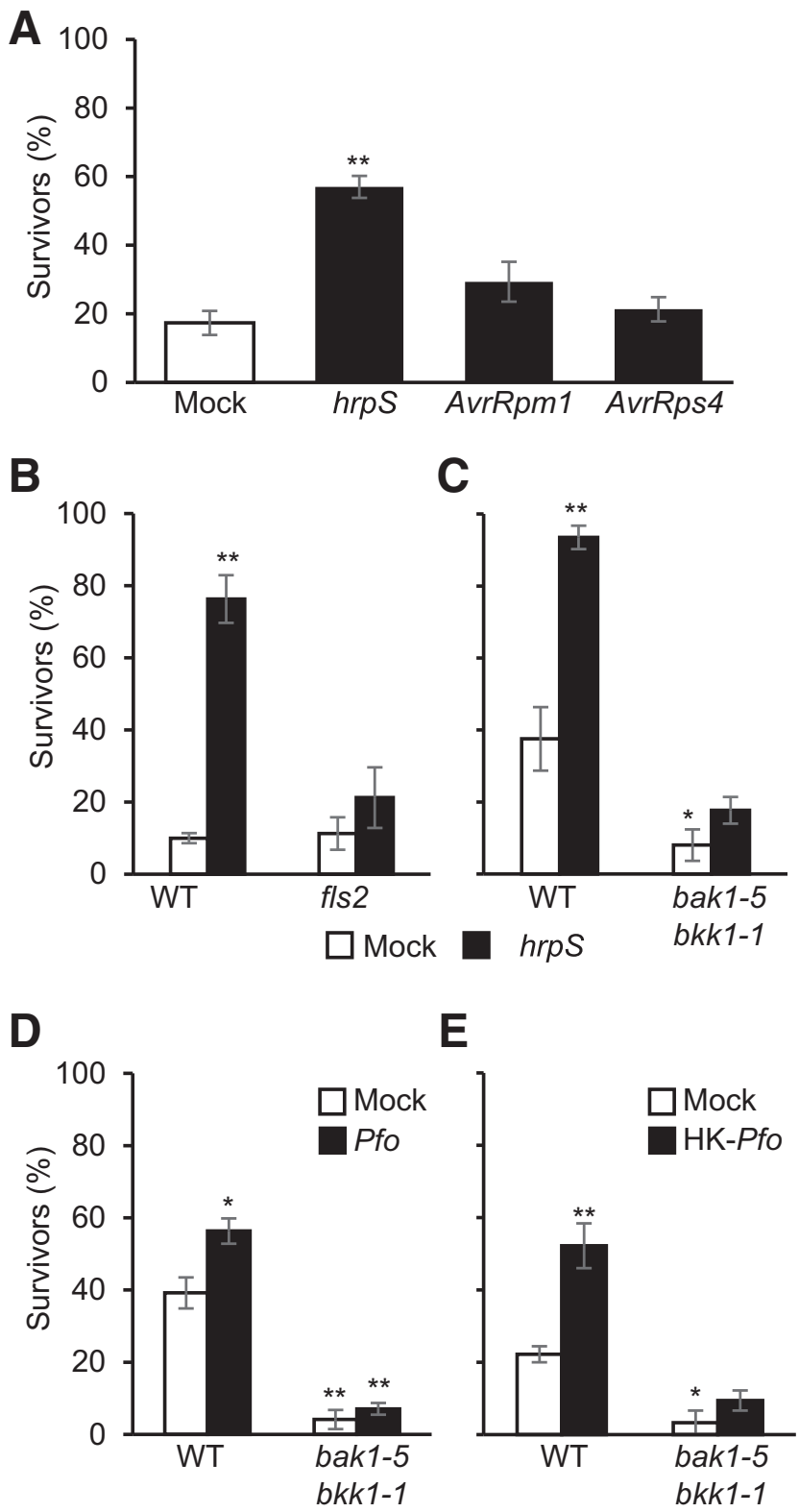

E

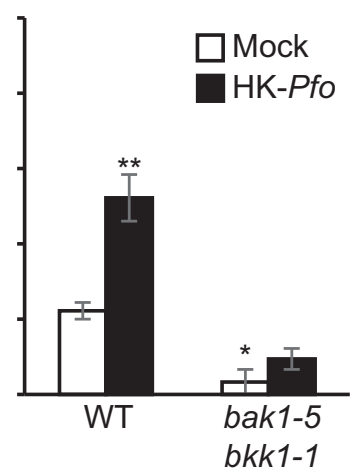

Fig. 6. Nonpathogenic bacteria confer salt tolerance through the host pattern recognition receptors PRRs and pattern-triggered immunity signaling components. A, Survival rate (mean \pm standard error of the mean [s.e.m.], $n \geq 25$, three replicates) of wild-type (WT) seedlings after 5 days of exposure to $175 \mathrm{mM} \mathrm{NaCl}$ following preinoculation with the indicated Pseudomonas syringae pv. tomato DC3000 strains. Asterisks (**) indicate $P<0.01$ using Tukey's honestly significant difference (HSD) tests compared with the values of the mock control. B to E, Survival rate (mean \pm s.e.m., $n \geq 20$, three replicates in $\mathrm{C}$ to $\mathrm{E}$ and four replicates in $\mathrm{B}$ ) of seedlings exposed to $175 \mathrm{mM} \mathrm{NaCl}$ for 5 days (B to D) and 4 days (E) following inoculation with the indicated live or dead bacteria. HK-P. simiae $=$ heat-killed $P$. simiae. Asterisks $(* *$ and $*$ ) indicate $P<0.01$ and 0.05 , respectively, using Tukey's HSD tests compared with the values of mocktreated WT plants. which was abolished in bakl-5 bkkl plants (Fig. 6D). The results suggest that the PRR signaling module becomes engaged in response to bacterial challenge, thereby conferring salt tolerance.

Finally, we tested whether bacterial MAMP recognition without live bacteria is sufficient to acquire salt tolerance. Indeed, preinoculation with heat-killed $P$. simiae enhanced salt tolerance in a $B A K 1$ - and $B K K 1$-dependent manner (Fig. 6E). Collectively, these results suggest that PRRs are important for salt stress sensing and adaptation when recognizing molecular patterns derived from the host-associated microbes or cellular damage.

\section{DISCUSSION}

Immune receptor activation can positively or negatively influence abiotic stress responses, yet the molecular logic behind this signaling plasticity remains poorly understood. Here, we showed that PRR signaling triggers an enhanced or primed state of salt stress tolerance in plants (Figs. 1 and 3; Table 1). Several lines of evidence indicate that PTST and PTI share previously described key steps within and proximal to the receptor complexes, at least for three $B A K 1$-dependent PRR pathways. A failure to mount PTST in the bakl-5 mutant and in the absence of $B I K 1 / P B L 1$ or $R B O H D$ indicates that PTST is achieved by authentic PRR signaling (Figs. 2, 3, and 6). Effective crosstolerance to biotic and salt stresses following PRR signaling may reflect similar cellular states and requirements in these stress conditions. This notion is supported by a substantial overlap between the pattern-induced and salt-induced transcriptomes (Fig. 5; Supplementary Fig. S1). Recent study also reported that rapidly induced genes in response to different MAMPs or DAMPs tend to be also induced under various abiotic stresses (Bjornson et al. 2021). Consistently, pattern recognition leads to the sensitization of salt-responsive genes and mobilization of otherwise nonresponsive genes, most prominently during early responses to salt stress (Fig. 5; Supplementary Figs. S1 and S3). These findings indicate rapid activation and expansion of the salt-responsive transcriptome as an important basis for PTST. By focusing on genes whose salt induction is strengthened or accelerated following Pep1 application, we revealed an interesting set of PTST-characteristic DEGs (Fig. 5D; Supplementary Table S1).

DAMPs represent a common signature of biotic and abiotic stress conditions in animals and plants (De Lorenzo et al. 2018; Gust et al. 2017). In plants, abiotic modulation of cell walls and phospholipid membranes generates a battery of DAMPs (Y.-L. Chen et al. 2020; Herger et al. 2019; Jiang et al. 2019; Rui and Dinneny 2020). Although the identity of cognate DAMP ligands remains elusive, different RKs are involved in mediating PTIlike defense responses and salt tolerance under salt stress conditions (Engelsdorf et al. 2018; Feng et al. 2018; Van der Does et al. 2017). Here, we showed that PROPEP3, together with short fragments likely containing its C-terminal Pep3 epitope, is released following salt stress, without microbes or exogenous MAMP or DAMP application (Fig. 4A and B). PROPEP2 and $P R O P E P 3$ expression represents an important preparatory step for positive feedback of defense signaling through PEPRs (Ross et al. 2014). PROPRP2 and PROPEP3 were among the 343 genes displaying faster salt induction following PRR activation (Supplementary Fig. S3C), pointing to a role for the PEPR pathway in rapid mobilization of salt-adaptive responses during PTST. Indeed, PEPRs provide a rate-limiting step in salt tolerance and salt-induced osmotic stress tolerance, both under sterile conditions (Fig. 4C and D). Genetic requirements for BAK1 and $B I K 1 / P B L 1$ (Figs. 2, 3, and 6C to E) are consistent with the involvement of $B A K 1 / B I K 1$-dependent DAMP receptors, including PEPRs, in salt tolerance. These findings strengthen the view that PRRs contribute to salt tolerance. 
Shared use of common signaling components between PTI and salt tolerance extends beyond BAKI- and BIK1-dependent PRR pathways. Glycosyl inositol phosphorylceramide sphingolipids provide $\mathrm{Na}^{+}$sensors to induce $\mathrm{Ca}^{2+}$ influx for SOS signaling under salt stress (Jiang et al. 2019), and also perception sites for bacterial-fungal-oomycete necrosis and ethylene-inducing peptide 1-like proteins (Lenarčič et al. 2017). Salt tolerance is dependent on the Catharanthus roseus RK FER (Feng et al. 2018; Zhao et al. 2018). FER recognizes immunostimulatory and immunosuppressive members of the endogenous RALF peptides and also scaffolds different PRR complexes (Haruta et al. 2014; Stegmann et al. 2017). FER-mediated salt tolerance depends, in part, on its ability to bind pectin and protect pectin crosslinking, suggesting its role in the sensing and management of cell wall integrity under salt stress (Feng et al. 2018). Following S1P subtilase cleavage, RALF22 and RALF23 are released from LRR-containing extensins LRX3, LRX4, and LRX5, thereby lowering salt tolerance through FER (Zhao et al. 2018). Notably, S1P-cleaved RALF members attenuate both FERmediated salt tolerance and PTI (Stegmann et al. 2017; Zhao et al. 2018). These studies further highlight the resemblance of PTI and salt stress signaling. Under our conditions, however, chitin signaling preactivation failed to confer salt tolerance. The apparent discrepancy between our and previous studies of chitinor CERK1-mediated salt tolerance (Supplementary Fig. S1) (Brotman et al. 2012; Espinoza et al. 2017) might reflect a divergence between different ectodomain classes of PRRs in their optimal conditions for salt tolerance, as seen in their regulation of immunity (Saijo et al. 2018).

Successful induction of PTST by PRR recognition of bacterial MAMPs, but not by NLR recognition of their effectors (Figs. 3 and 6), fits with the idea that strong activation of immunity negatively influences salt tolerance. This is in line with previous studies that EDS1- and PAD4-mediated defense activation results in the collapse of osmotic stress tolerance (Ariga et al. 2017). This cross-tolerance trade-off predicts the existence of a critical threshold beyond which further immune activation comes at a cost for salt and osmotic stress tolerance. Recent studies show that PRR signaling provides an integrating basis for ETI, and that mutual PTI and ETI potentiation is required for effective pathogen resistance (Ngou et al. 2021; Yuan et al. 2021). At present, how NLR signaling exceeds the predicted threshold during ETI remains poorly understood.

Mostly from soil microbes, plants selectively recruit and modify their root-associated microbiota during adaptation to different stress conditions (Shilev 2020). It is conceivable that these changes under salt stress are accompanied by alterations in the presentation of MAMPs or DAMPs in the extracellular milieu, as shown for PROPEP3 (Fig. 4B), which are sensed and linked by PRRs to adaptive responses to salt stress. It has been described that nonpathogenic microbes serve to alleviate salt stress in the host plant (Egamberdieva et al. 2019; Fan et al. 2020; Zuccaro et al. 2011). In addition to the beneficial activities of specific plant-associated bacteria, our work indicates that PRR recognition of bacterial MAMPs, not their live activities, leads to plant salt tolerance. This study unravels a fraction of plant-microbe-environment interactions, in which endogenous or microbial immunogenic patterns generated under salt stress likely engage PRRs in promoting salt or osmotic stress tolerance, in part by priming the activation of a salt-adaptive transcriptome (Figs. 5C and 7).

\section{MATERIALS AND METHODS}

\section{Plant materials and growth conditions.}

The A. thaliana accession Col-0 was used as the WT. Plant materials used are provided in Supplementary Table S4. Seeds were sterilized with $6 \%$ sodium hypochlorite and $0.1 \%$ Triton
X-100 for $15 \mathrm{~min}$, rinsed five times with autoclaved distilled water, and stratified at $4^{\circ} \mathrm{C}$ for 2 to 5 days before use. The growth medium used was Murashige and Skoog (MS) medium (half-strength MS basal salts, $25 \mathrm{mM}$ sucrose, and morpholineethanesulfonic acid at $0.5 \mathrm{~g} /$ liter; $\mathrm{pH}$ 5.7) unless otherwise stated. Plants were grown under $14 \mathrm{~h}$ of light and $10 \mathrm{~h}$ of darkness at $22^{\circ} \mathrm{C}$ unless otherwise stated. For detection of extracellular PROPEP3-Venus protein, 2-week-old seedlings in liquid growth media were exposed to $0.5 \mu \mathrm{M}$ Pep1 for 3 days, $150 \mathrm{mM} \mathrm{NaCl}$ for 3 days or $0.5 \mu \mathrm{M}$ Pep1 for $12 \mathrm{~h}$, followed by $150 \mathrm{mM} \mathrm{NaCl}$ for 3 days under standard growth conditions.

\section{Pattern-triggered salt tolerance assay.}

Four-day-old seedlings in the liquid growth media were treated with the indicated elicitors $(0.1 \mu \mathrm{M}$ Peps, flg22, or elf18 and chitin at $100 \mu \mathrm{g} / \mathrm{ml})$. For treatment with heat-killed bacteria, bacteria cultivated (as described below) up to an optical density at $590 \mathrm{~nm}\left(\mathrm{OD}_{590}\right)=0.2$ were collected, suspended, and then autoclaved at $121^{\circ} \mathrm{C}$ for $20 \mathrm{~min}$. The supernatants after centrifugation were recovered for use. Four days after elicitor or bacterium treatments, seedlings were transferred to the agar growth media supplemented with 150 or $175 \mathrm{mM} \mathrm{NaCl}$. The number of viable seedlings was scored every day for the indicated duration.

\section{Salt stress}

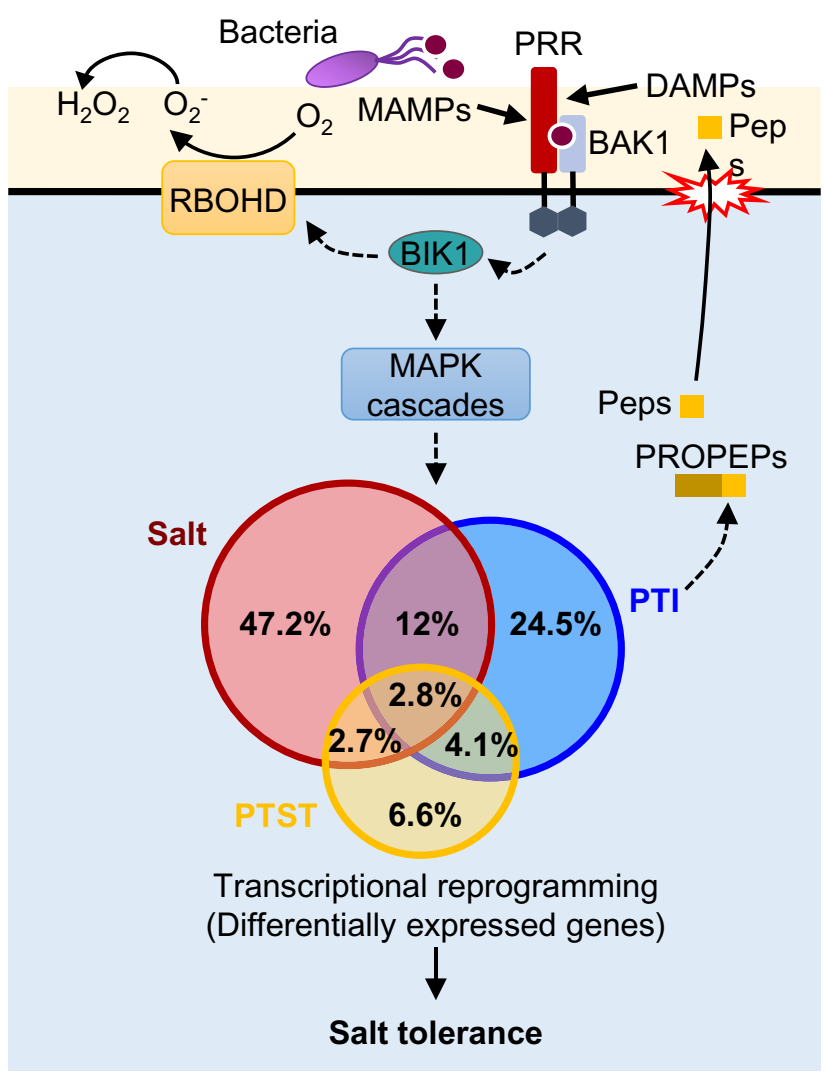

Fig. 7. A model for a pattern recognition receptor (PRR) signaling cascade during pattern-triggered salt tolerance (PTST). Following the recognition of cognate microbe-associated molecular pattern (MAMP) or damageassociated molecular pattern (DAMP) ligands, PRRs trigger signaling cascades through previously described PRR complexes and signaling regulators, which lead to primed and rapid activation of the salt-adaptive transcriptome during PTST, summarized in a Venn diagram. MAPK = mitogen-activated protein kinase. Our findings propose that DAMPs from cellular damage and MAMPs from plant-associated microbes under salt stress involve PRRs in signaling toward salt stress tolerance. Dotted lines indicate the actions or links hypothesized. 
Survival ratio was determined as the number of viable seedlings relative to the total number of seedlings used. For fresh weight determination, seedlings were pooled for weighing and the average weight per seedling was determined by dividing the weight by the number of seedlings pooled. Chlorophyll contents were determined essentially as described previously (Porra et al. 1989), except that the chlorophyll contents were normalized by the number of seedlings used.

\section{Acquired osmotic tolerance assay.}

Assays for salt-induced osmotic stress tolerance were performed as described by Ariga et al. (2017). In brief, 7-day-old seedlings were transferred from agar growth media to that supplemented with $100 \mathrm{mM} \mathrm{NaCl}$, and further incubated for 7 days. Seedlings were then transferred to that supplemented with $750 \mathrm{mM}$ sorbitol, and grown for another 14 days before the determination of chlorophyll contents.

\section{Quantitative reverse-transcription PCR analysis.}

Total RNA was extracted from plant samples with Purelink (Nacalai Tesque) and reverse transcribed with PrimeScript Reagent Kit Perfect Real Time (Takara) according to the manufacturer's instructions. Quantitative reverse-transcription PCR was performed with Power SYBR Green PCR Master Mix (Applied Biosystems) using the Thermal Cycler Dice RealTime TP870 (Takara) under the following conditions: $50^{\circ} \mathrm{C}$ for $2 \mathrm{~min}$, $95^{\circ} \mathrm{C}$ for $10 \mathrm{~min}, 95^{\circ} \mathrm{C}$ for $15 \mathrm{~s}$, followed by $60^{\circ} \mathrm{C}$ for $1 \mathrm{~min}$ for 40 cycles; then, $95^{\circ} \mathrm{C}$ for $15 \mathrm{~s}, 60^{\circ} \mathrm{C}$ for $30 \mathrm{~s}$, and, finally, $95^{\circ} \mathrm{C}$ for $15 \mathrm{~s}$. The primers used are provided in Supplementary Table S4.

\section{Protein extraction and immunoblot analysis.}

Protein extracts were prepared by homogenizing frozen tissues in a lysis buffer $(50 \mathrm{mM}$ Tris- $\mathrm{HCl}[\mathrm{pH} 7.5], 2 \%$ sodium dodecyl sulfate [SDS], $2 \mathrm{mM}$ dithiothreitol, $2.5 \mathrm{mM} \mathrm{NaF}$, and P9599 protease inhibitor cocktail [Sigma]) for $15 \mathrm{~min}$ at room temperature. The supernatants recovered after centrifugation at $13,000 \times g$ for 15 min were subjected to immunoblot analysis on $10 \%$ SDS polyacrylamide gel electrophoresis with the indicated antibodies, listed below. Molecular weight marker used was Protein Ladder One (triple-color; Nacalai Tesque). Anti-HA (3F10) antibody was purchased from Roche. Anti-PROPEP3 antibodies raised in rabbits against both $\mathrm{N}$ - and C-terminal fragments of PROPEP3 were described previously (Ross et al. 2014). For detection of extracellular PROPEP3-Venus pool, protein concentrated from the liquid media with Strataclean resin (Agilent Technologies) after filtration was used as an extracellular fraction.

\section{RNA sequencing and analysis.}

Five-day-old seedlings grown as described above were pretreated with $0.1 \mu \mathrm{M}$ Pep1 for 3 days, then exposed to $150 \mathrm{mM}$ $\mathrm{NaCl}$ for the indicated times. Three biological replicates were prepared per treatment and genotype. Total RNA was extracted with an RNA extraction kit following the manufacturer's procedures (NucleoSpin RNA; Machery-Nagel). Each cDNA library was prepared using a TruSeq RNA Library Prep Kit v2 following the manufacturer's procedures (Illumina). High-throughput sequencing was run by a single-read 50-bp on a HiSeq2500 platform (Illumina). Raw sequence data were deposited in the DNA Data Bank of Japan Sequence Read Archive (accession number DRA004299). Reads were mapped to the TAIR9 Arabidopsis transcriptome database. The edgeR software package was used for estimation of false discovery rate (FDR) for differential gene expression of raw reads from all three biological replicates.

All mRNA variants detected from a gene locus were defined as separate genes in RNA sequencing (RNA-seq) analyses but assembled and scored for the one gene locus in cross-referencing
RNA-seq and ChIP-seq data. For instance, 343 genes were scored as DEGs displaying faster salt induction after Pep1 pretreatment in our RNA-seq analysis, whereas they were scored as 329 genes corresponding to their loci in the cross-referenced ChIP-seq data. A heatmap was generated with an R software heat map tool from the gplot package, with DEGs identified using the following cut-off values: FDR $<0.05$, expression $\log _{2} \mathrm{FC} \geq 1$ ], and Student's $t$ test $P<0.05$. Gene read counts were normalized to reads per kilobase million values, and hierarchical clustering was conducted with one minus Pearson correlation complete linkage.

\section{Bacterial inoculation for salt tolerance assay.}

P. syringae DC3000 $\Delta$ hrpS (Jovanovic et al. 2011), AvrRpml (Debener et al. 1991), and AvrRps4 (Sohn et al. 2009) and P. simiae WCS417 (Berendsen et al. 2015) were grown in media consisting of peptone at $5 \mathrm{~g} /$ liter, yeast extract at $3 \mathrm{~g} /$ liter, glycerol at $20 \mathrm{ml} /$ liter, $\mathrm{pH}$ 7.0, supplemented with appropriate antibiotics (rifampicin at $25 \mathrm{mg} / \mathrm{ml}$ in dimethyl sulfoxide, kanamycin at $50 \mathrm{mg} / \mathrm{ml}$ in deionized distilled water, tetracycline at $15 \mathrm{mg} / \mathrm{liter}$ in ethanol, or chloramphenicol at $30 \mathrm{mg} / \mathrm{ml}$ in ethanol). Overnight bacterial cultures were washed at least twice with $10 \mathrm{mM} \mathrm{MgCl} 2$ and then adjusted to $\mathrm{OD}_{590}=0.002$ for spray inoculation. Seedlings were transferred from liquid growth media to agar plates 1 day prior to spray inoculation. At $6 \mathrm{~h}$ after inoculation, seedlings were surface sterilized twice with $70 \%$ ethanol, rinsed twice with autoclaved $\mathrm{H}_{2} \mathrm{O}$, and then transferred to agar media supplemented with or without $175 \mathrm{mM} \mathrm{NaCl}$.

\section{ACKNOWLEDGMENTS}

We thank the Saijo Lab members for technical assistance and insightful discussions; Y. Fujita, F. Katagiri, J.-M. Zhou, and C. Zipfel for published materials; and the Cooperative Research Program of the Genome Research for BioResource, NODAI Genome Research Center, Tokyo University of Agriculture, for their support of the RNA sequencing.

\section{AUTHOR-RECOMMENDED INTERNET RESOURCES}

edgeR software package: https://bioconductor.org/packages/release/bioc/ html/edgeR.html

gplot package: https://cran.r-project.org/web/packages/gplots/

TAIR9 Arabidopsis transcriptome database: https://www.arabidopsis.org

\section{LITERATURE CITED}

Acosta-Motos, J. R., Ortuño, M. F., Bernal-Vicente, A., Diaz-Vivancos, P., Sanchez-Blanco, M. J., and Hernandez, J. A. 2017. Plant responses to salt stress: Adaptive mechanisms. Agronomy (Basel) 7:18.

Ariga, H., Katori, T., Tsuchimatsu, T., Hirase, T., Tajima, Y., Parker, J. E., Alcázar, R., Koornneef, M., Hoekenga, O., Lipka, A. E., Gore, M. A., Sakakibara, H., Kojima, M., Kobayashi, Y., Iuchi, S., Kobayashi, M., Shinozaki, K., Sakata, Y., Hayashi, T., Saijo, Y., and Taji, T. 2017 NLR locus-mediated trade-off between abiotic and biotic stress adaptation in Arabidopsis. Nat. Plants 3:17072.

Aslam, S. N., Erbs, G., Morrissey, K. L., Newman, M. A., Chinchilla, D., Boller, T., Molinaro, A., Jackson, R. W., and Cooper, R. M. 2009. Microbe-associated molecular pattern (MAMP) signatures, synergy, size and charge: Influences on perception or mobility and host defence responses. Mol. Plant Pathol. 10:375-387.

Bailey, T. L., and Machanick, P. 2012. Inferring direct DNA binding from ChIP-seq. Nucleic Acids Res. 40:e128.

Bartels, S., Lori, M., Mbengue, M., van Verk, M., Klauser, D., Hander, T., Böni, R., Robatzek, S., and Boller, T. 2013. The family of Peps and their precursors in Arabidopsis: Differential expression and localization but similar induction of pattern-triggered immune responses. J. Exp. Bot. 64:5309-5321.

Bartsch, M., Gobbato, E., Bednarek, P., Debey, S., Schultze, J. L., Bautor, J., and Parker, J. E. 2006. Salicylic acid-independent ENHANCED DISEASE SUSCEPTIBILITY1 signaling in Arabidopsis immunity and cell death is regulated by the monooxygenase FMOI and the Nudix hydrolase NUDT7. Plant Cell 18:1038-1051. 
Berendsen, R. L., van Verk, M. C., Stringlis, I. A., Zamioudis, C., Tommassen, J., Pieterse, C. M., and Bakker, P. A. 2015. Unearthing the genomes of plant-beneficial Pseudomonas model strains WCS358, WCS374 and WCS417. BMC Genomics 16:539.

Birkenbihl, R. P., Kracher, B., Roccaro, M., and Somssich, I. E. 2017. Induced genome-wide binding of three Arabidopsis WRKY transcription factors during early MAMP-triggered immunity. Plant Cell 29:2038 .

Bjornson, M., Pimprikar, P., Nürnberger, T., and Zipfel, C. 2021. The transcriptional landscape of Arabidopsis thaliana pattern-triggered immunity. Nat. Plants. 7:579-586.

Boller, T., and Felix, G. 2009. A renaissance of elicitors: Perception of microbe-associated molecular patterns and danger signals by patternrecognition receptors. Annu. Rev. Plant Biol. 60:379-406.

Brotman, Y., Landau, U., Pnini, S., Lisec, J., Balazadeh, S., MuellerRoeber, B., Zilberstein, A., Willmitzer, L., Chet, I., and Viterbo, A. 2012. The LysM receptor-like kinase LysM RLK1 is required to activate defense and abiotic-stress responses induced by overexpression of fungal chitinases in Arabidopsis plants. Mol. Plant 5:1113-1124.

Chen, K., Gao, J., Sun, S., Zhang, Z., Yu, B., Li, J., Xie, C., Li, G. Wang, P., Song, C.-P., Bressan, R. A., Hua, J., Zhu, J.-K., and Yang, Z. 2020. BONZAI proteins control global osmotic stress responses in plants. Curr. Biol. 30:4815-4825.E4.

Chen, Y.-L., Fan, K.-T., Hung, S.-C., and Chen, Y.-R. 2020. The role of peptides cleaved from protein precursors in eliciting plant stress reactions. New Phytol. 225:2267-2282.

Couto, D., and Zipfel, C. 2016. Regulation of pattern recognition receptor signalling in plants. Nat. Rev. Immunol. 16:537-552.

Cui, H., Gobbato, E., Kracher, B., Qiu, J., Bautor, J., and Parker, J. E. 2017 A core function of EDS1 with PAD4 is to protect the salicylic acid defense sector in Arabidopsis immunity. New Phytol. 213:1802-1817.

Cui, H., Tsuda, K., and Parker, J. E. 2015. Effector-triggered immunity: From pathogen perception to robust defense. Annu. Rev. Plant Biol. 66:487-511

Cutler, S. R., Rodriguez, P. L., Finkelstein, R. R., and Abrams, S. R 2010. Abscisic acid: Emergence of a core signaling network. Annu. Rev. Plant Biol. 61:651-679.

Debener, T., Lehnackers, H., Arnold, M., and Dangl, J. L. 1991. Identification and molecular mapping of a single Arabidopsis thaliana locus determining resistance to a phytopathogenic Pseudomonas syringae isolate. Plant J. 1:289-302.

DeFalco, T. A., and Zipfel, C. 2021. Molecular mechanisms of early plant pattern-triggered immune signaling. Mol. Cell 81:3449-3467.

De Lorenzo, G., Ferrari, S., Cervone, F., and Okun, E. 2018. Extracellular DAMPs in plants and mammals: Immunity, tissue damage and repair. Trends Immunol. 39:937-950.

Ding, P., and Ding, Y. 2020. Stories of salicylic acid: A plant defense hormone. Trends Plant Sci. 25:549-565.

Dongus, J. A., and Parker, J. E. 2021. EDS1 signalling: At the nexus of intracellular and surface receptor immunity. Curr. Opin. Plant Biol. 62:102039.

Egamberdieva, D., Wirth, S., Bellingrath-Kimura, S. D., Mishra, J., and Arora, N. K. 2019. Salt-tolerant plant growth promoting rhizobacteria for enhancing crop productivity of saline soils. Front. Microbiol. 10:2791.

Engelsdorf, T., Gigli-Bisceglia, N., Veerabagu, M., McKenna, J. F., Vaahtera, L., Augstein, F., Van der Does, D., Zipfel, C., and Hamann, T. 2018. The plant cell wall integrity maintenance and immune signaling systems cooperate to control stress responses in Arabidopsis thaliana. Sci. Signal. 11:eaao3070.

Espinoza, C., Liang, Y., and Stacey, G. 2017. Chitin receptor CERK1 links salt stress and chitin-triggered innate immunity in Arabidopsis. Plant J. 89:984-995.

Fan, D., Subramanian, S., and Smith, D. L. 2020. Plant endophytes promote growth and alleviate salt stress in Arabidopsis thaliana. Sci. Rep. 10:12740.

Feng, W., Kita, D., Peaucelle, A., Cartwright, H. N., Doan, V., Duan, Q., Liu, M. C., Maman, J., Steinhorst, L., Schmitz-Thom, I., Yvon, R., Kudla, J., Wu, H. M., Cheung, A. Y., and Dinneny, J. R. 2018. The FERONIA receptor kinase maintains cell-wall integrity during salt stress through $\mathrm{Ca}^{2+}$ signaling. Curr. Biol. 28:666-675.e5.

Finkelstein, R. 2013. Abscisic acid synthesis and response. Arabidopsis Book 11:e0166.

Gassmann, W., Hinsch, M. E., and Staskawicz, B. J. 1999. The Arabidopsis RPS4 bacterial-resistance gene is a member of the TIR-NBS-LRR family of disease-resistance genes. Plant J. 20:265-277.

Geng, Y., Wu, R., Wee, C. W., Xie, F., Wei, X., Chan, P. M., Tham, C., Duan, L., and Dinneny, J. R. 2013. A spatio-temporal understanding of growth regulation during the salt stress response in Arabidopsis. Plant Cell 25:2132-2154.

Glazebrook, J., Chen, W., Estes, B., Chang, H. S., Nawrath, C., Métraux, J. P., Zhu, T., and Katagiri, F. 2003. Topology of the network integrating salicylate and jasmonate signal transduction derived from global expression phenotyping. Plant J. 34:217-228.

Gómez-Gómez, L., and Boller, T. 2000. FLS2: An LRR receptor-like kinase involved in the perception of the bacterial elicitor flagellin in Arabidopsis. Mol. Cell 5:1003-1011.

Gómez-Gómez, L., Felix, G., and Boller, T. 1999. A single locus determines sensitivity to bacterial flagellin in Arabidopsis thaliana. Plant J. 18:277-284.

González-Guzmán, M., Apostolova, N., Bellés, J. M., Barrero, J. M., Piqueras, P., Ponce, M. R., Micol, J. L., Serrano, R., and Rodríguez, P. L. 2002. The short-chain alcohol dehydrogenase ABA2 catalyzes the conversion of xanthoxin to abscisic aldehyde. Plant Cell 14: 1833-1846.

Grant, M. R., Godiard, L., Straube, E., Ashfield, T., Lewald, J., Sattler, A., Innes, R. W., and Dangl, J. L. 1995. Structure of the Arabidopsis RPM1 gene enabling dual specificity disease resistance. Science 269: 843-846.

Guo, Q., Liu, L., and Barkla, B. J. 2019. Membrane lipid remodeling in response to salinity. Int. J. Mol. Sci. 20:4264.

Gust, A. A., Pruitt, R., and Nürnberger, T. 2017. Sensing danger: Key to activating plant immunity. Trends Plant Sci. 22:779-791.

Hander, T., Fernández-Fernández, Á. D., Kumpf, R. P., Willems, P. Schatowitz, H., Rombaut, D., Staes, A., Nolf, J., Pottie, R., Yao, P., Gonçalves, A., Pavie, B., Boller, T., Gevaert, K., Van Breusegem, F. Bartels, S., and Stael, S. 2019. Damage on plants activates $\mathrm{Ca}^{2+}$ dependent metacaspases for release of immunomodulatory peptides. Science 363:eaar7486.

Haruta, M., Sabat, G., Stecker, K., Minkoff, B. B., and Sussman, M. R. 2014. A peptide hormone and its receptor protein kinase regulate plant cell expansion. Science 343:408-411.

Herger, A., Dünser, K., Kleine-Vehn, J., and Ringli, C. 2019. Leucinerich repeat extensin proteins and their role in cell wall sensing. Curr Biol. 29:R851-R858.

Hou, Q., Ufer, G., and Bartels, D. 2016. Lipid signalling in plant responses to abiotic stress. Plant Cell Environ. 39:1029-1048

Hutcheson, S. W., Bretz, J., Sussan, T., Jin, S., and Pak, K. 2001. Enhancer-binding proteins HrpR and HrpS interact to regulate hrpencoded type III protein secretion in Pseudomonas syringae strains. J. Bacteriol. 183:5589-5598.

Jiang, Z., Zhou, X., Tao, M., Yuan, F., Liu, L., Wu, F., Wu, X., Xiang, Y., Niu, Y., Liu, F., Li, C., Ye, R., Byeon, B., Xue, Y., Zhao, H., Wang, H. N., Crawford, B. M., Johnson, D. M., Hu, C., Pei, C., Zhou, W., Swift, G. B., Zhang, H., Vo-Dinh, T., Hu, Z., Siedow, J. N., and Pei, Z. M. 2019. Plant cell-surface GIPC sphingolipids sense salt to trigger $\mathrm{Ca}^{2+}$ influx. Nature 572:341-346.

Jones, J. D., and Dangl, J. L. 2006. The plant immune system. Nature 444:323-329.

Jones, J. D., Vance, R. E., and Dangl, J. L. 2016. Intracellular innate immune surveillance devices in plants and animals. Science 354 aaf6395.

Jovanovic, M., James, E. H., Burrows, P. C., Rego, F. G., Buck, M., and Schumacher, J. 2011. Regulation of the co-evolved HrpR and HrpS AAA+ proteins required for Pseudomonas syringae pathogenicity. Nat. Commun. 2:177.

Kadota, Y., Shirasu, K., and Zipfel, C. 2015. Regulation of the NADPH oxidase RBOHD during plant immunity. Plant Cell Physiol. 56:14721480

Karim, S., Holmström, K. O., Mandal, A., Dahl, P., Hohmann, S., Brader, G., Palva, E. T., and Pirhonen, M. 2007. AtPTR3, a woundinduced peptide transporter needed for defence against virulent bacterial pathogens in Arabidopsis. Planta 225:1431-1445.

Karim, S., Lundh, D., Holmström, K. O., Mandal, A., and Pirhonen, M. 2005. Structural and functional characterization of AtPTR3, a stressinduced peptide transporter of Arabidopsis. J. Mol. Model. 11:226-236.

Kim, M. G., da Cunha, L., McFall, A. J., Belkhadir, Y., DebRoy, S., Dangl, J. L., and Mackey, D. 2005. Two Pseudomonas syringae type III effectors inhibit RIN4-regulated basal defense in Arabidopsis. Cell 121:749-759.

Krol, E., Mentzel, T., Chinchilla, D., Boller, T., Felix, G., Kemmerling, B., Postel, S., Arents, M., Jeworutzki, E., Al-Rasheid, K. A., Becker, D., and Hedrich, R. 2010. Perception of the Arabidopsis danger signal peptide 1 involves the pattern recognition receptor AtPEPR 1 and its close homologue AtPEPR2. J. Biol. Chem. 285:13471-13479. 
Lee, H. J., Park, Y. J., Seo, P. J., Kim, J. H., Sim, H. J., Kim, S. G., and Park, C. M. 2015. Systemic immunity requires SnRK2.8-mediated nuclear import of NPR1 in Arabidopsis. Plant Cell 27:3425-3438.

Lenarčič, T., Albert, I., Böhm, H., Hodnik, V., Pirc, K., Zavec, A. B., Podobnik, M., Pahovnik, D., Žagar, E., Pruitt, R., Greimel, P., Yamaji-Hasegawa, A., Kobayashi, T., Zienkiewicz, A., Gömann, J., Mortimer, J. C., Fang, L., Mamode-Cassim, A., Deleu, M., Lins, L., Oecking, C., Feussner, I., Mongrand, S., Anderluh, G., and Nürnberger, T. 2017. Eudicot plant-specific sphingolipids determine host selectivity of microbial NLP cytolysins. Science 358:1431-1434.

Nakaminami, K., Okamoto, M., Higuchi-Takeuchi, M., Yoshizumi, T., Yamaguchi, Y., Fukao, Y., Shimizu, M., Ohashi, C., Tanaka, M., Matsui, M., Shinozaki, K., Seki, M., and Hanada, K. 2018. AtPep3 is a hormone-like peptide that plays a role in the salinity stress tolerance of plants. Proc. Natl. Acad. Sci. U.S.A. 115:5810-5815.

Ngou, B. P. M., Ahn, H.-K., Ding, P., and Jones, J. D. G. 2021. Mutual potentiation of plant immunity by cell-surface and intracellular receptors. Nature 592:110-115.

Pieterse, C. M., Van der Does, D., Zamioudis, C., Leon-Reyes, A., and Van Wees, S. C. 2012. Hormonal modulation of plant immunity. Annu. Rev. Cell Dev. Biol. 28:489-521.

Porra, R. J., Thompson, W. A., and Kriedemann, P. E. 1989. Determination of accurate extinction coefficients and simultaneous equations for assaying chlorophylls a and b extracted with four different solvents: Verification of the concentration of chlorophyll standards by atomic absorption spectroscopy. BBA-Bioenergetics 975:384-394.

Rauf, M., Arif, M., Fisahn, J., Xue, G.-P., Balazadeh, S., and MuellerRoeber, B. 2013. NAC transcription factor SPEEDY HYPONASTIC GROWTH regulates flooding-induced leaf movement in Arabidopsis. Plant Cell. 12:4951-4555.

Ross, A., Yamada, K., Hiruma, K., Yamashita-Yamada, M., Lu, X., Takano, Y., Tsuda, K., and Saijo, Y. 2014. The Arabidopsis PEPR pathway couples local and systemic plant immunity. EMBO J. 33:62-75.

Roux, M., Schwessinger, B., Albrecht, C., Chinchilla, D., Jones, A., Holton, N., Malinovsky, F. G., Tör, M., de Vries, S., and Zipfel, C. 2011. The Arabidopsis leucine-rich repeat receptor-like kinases BAK1/SERK3 and BKK1/SERK4 are required for innate immunity to hemibiotrophic and biotrophic pathogens. Plant Cell 23:2440-2455

Rui, Y., and Dinneny, J. R. 2020. A wall with integrity: Surveillance and maintenance of the plant cell wall under stress. New Phytol. 225:14281439.

Saijo, Y., and Loo, E. P. 2020. Plant immunity in signal integration between biotic and abiotic stress responses. New Phytol. 225:87-104.

Saijo, Y., Loo, E. P., and Yasuda, S. 2018. Pattern recognition receptors and signaling in plant-microbe interactions. Plant J. 93:592-613.

Saucet, S. B., Ma, Y., Sarris, P. F., Furzer, O. J., Sohn, K. H., and Jones, J. D. G. 2015. Two linked pairs of Arabidopsis TNL resistance genes independently confer recognition of bacterial effector AvrRps4. Nat. Commun. 6:6338.

Schwessinger, B., Roux, M., Kadota, Y., Ntoukakis, V., Sklenar, J., Jones, A., and Zipfel, C. 2011. Phosphorylation-dependent differential regulation of plant growth, cell death, and innate immunity by the regulatory receptor-like kinase BAK1. PLoS Genet. 7:e1002046.

Shilev, S. 2020. Plant-growth-promoting bacteria mitigating soil salinity stress in plants. Appl. Sci. 10:7326.

Sohn, K. H., Zhang, Y., and Jones, J. D. 2009. The Pseudomonas syringae effector protein, AvrRPS4, requires in planta processing and the KRVY domain to function. Plant J. 57:1079-1091.

Stegmann, M., Monaghan, J., Smakowska-Luzan, E., Rovenich, H., Lehner, A., Holton, N., Belkhadir, Y., and Zipfel, C. 2017. The receptor kinase FER is a RALF-regulated scaffold controlling plant immune signaling. Science 355:287-289.
Tsuda, K., Sato, M., Stoddard, T., Glazebrook, J., and Katagiri, F. 2009. Network properties of robust immunity in plants. PLoS Genet. 5: e1000772.

Umezawa, T., Yoshida, R., Maruyama, K., Yamaguchi-Shinozaki, K., and Shinozaki, K. 2004. SRK2C, a SNF1-related protein kinase 2, improves drought tolerance by controlling stress-responsive gene expression in Arabidopsis thaliana. Proc. Natl. Acad. Sci. U.S.A. 101: 17306-17311.

Van der Does, D., Boutrot, F., Engelsdorf, T., Rhodes, J., McKenna, J. F., Vernhettes, S., Koevoets, I., Tintor, N., Veerabagu, M., Miedes, E., Segonzac, C., Roux, M., Breda, A. S., Hardtke, C. S., Molina, A., Rep, M., Testerink, C., Mouille, G., Höfte, H., Hamann, T., and Zipfel, C. 2017. The Arabidopsis leucine-rich repeat receptor kinase MIK2/ LRR-KISS connects cell wall integrity sensing, root growth and response to abiotic and biotic stresses. PLoS Genet. 13:e1006832.

Velásquez, A. C., Castroverde, C. D. M., and He, S. Y. 2018. Plant-pathogen warfare under changing climate conditions. Curr. Biol. 28:R619-R634.

Vlot, A. C., Dempsey, D. A., and Klessig, D. F. 2009. Salicylic acid, a multifaceted hormone to combat disease. Annu. Rev. Phytopathol. 47: 177-206.

Wiermer, M., Feys, B. J., and Parker, J. E. 2005. Plant immunity: The EDS1 regulatory node. Curr. Opin. Plant Biol. 8:383-389.

Wildermuth, M. C., Dewdney, J., Wu, G., and Ausubel, F. M. 2001. Isochorismate synthase is required to synthesize salicylic acid for plant defence. Nature 414:562-565.

Yamada, K., Yamashita-Yamada, M., Hirase, T., Fujiwara, T., Tsuda, K., Hiruma, K., and Saijo, Y. 2016. Danger peptide receptor signaling in plants ensures basal immunity upon pathogen-induced depletion of BAK1. EMBO J. 35:46-61.

Yamaguchi, Y., Huffaker, A., Bryan, A. C., Tax, F. E., and Ryan, C. A. 2010. PEPR2 is a second receptor for the Pep1 and Pep2 peptides and contributes to defense responses in Arabidopsis. Plant Cell 22:508522.

Yamaguchi, Y., Pearce, G., and Ryan, C. A. 2006. The cell surface leucine-rich repeat receptor for AtPep1, an endogenous peptide elicitor in Arabidopsis, is functional in transgenic tobacco cells. Proc. Natl. Acad. Sci. U.S.A. 103:10104-10109.

Yoshida, T., Fujita, Y., Maruyama, K., Mogami, J., Todaka, D., Shinozaki, K., and Yamaguchi-Shinozaki, K. 2015. Four Arabidopsis AREB/ABF transcription factors function predominantly in gene expression downstream of SnRK2 kinases in abscisic acid signalling in response to osmotic stress. Plant Cell Environ. 38:35-49.

Yu, X., Feng, B., He, P., and Shan, L. 2017. From chaos to harmony: Responses and signaling upon microbial pattern recognition. Annu. Rev. Phytopathol. 55:109-137.

Yuan, M., Jiang, Z., Bi, G., Nomura, K., Liu, M., Wang, Y., Cai, B., Zhou, J. M., He, S. Y., and Xin, X. F. 2021. Pattern-recognition receptors are required for NLR-mediated plant immunity. Nature 592:105109.

Zhao, C., Zayed, O., Yu, Z., Jiang, W., Zhu, P., Hsu, C. C., Zhang, L., Tao, W. A., Lozano-Durán, R., and Zhu, J. K. 2018. Leucine-rich repeat extensin proteins regulate plant salt tolerance in Arabidopsis. Proc. Natl. Acad. Sci. U.S.A. 115:13123-13128.

Zipfel, C., Kunze, G., Chinchilla, D., Caniard, A., Jones, J. D. G., Boller, T., and Felix, G. 2006. Perception of the bacterial PAMP EF-Tu by the receptor EFR restricts Agrobacterium-mediated transformation. Cell 125:749-760.

Zuccaro, A., Lahrmann, U., Güldener, U., Langen, G., Pfiffi, S., Biedenkopf, D., Wong, P., Samans, B., Grimm, C., Basiewicz, M., Murat, C., Martin, F., and Kogel, K.-H. 2011. Endophytic life strategies decoded by genome and transcriptome analyses of the mutualistic root symbiont Piriformospora indica. PLoS Pathog. 7:e1002290. 